\title{
PRÁCTICA RITUAL Y TENSIONES IDENTITARIAS EN LAS DANZAS PROMESANTES DE LA FIESTA DEL SANTUARIO DE AYQUINA, NORTE DE CHILE*
}

\author{
RITUAL PRACTICE AND IDENTITY TENSIONS IN THE 'PROMESANTE' \\ DANCES OF THE AYQUINA'S SANCTUARY FIESTA, NORTHERN CHILE
}

\author{
Javier Mercado Guerra**
}

\begin{abstract}
El presente trabajo indaga en los significados identitarios asociados a las danzas promesantes ejecutadas durante la fiesta del santuario de Ayquina, provincia de El Loa, Región de Antofagasta, Chile. Asumiendo una perspectiva que enfatiza en las singularidades rituales de las danzas promesantes, el texto se adentra en el análisis de algunos soportes significantes característicos de la expresividad danzada -como patrones coreográficos, gestualidades, músicas y vestimentas-, en donde se propone la existencia de tres estilos predominantes: danzas de "antigua estirpe", danzas de "creación local" y danzas de "influencia boliviana reciente". En este sentido, una de las distinciones más relevantes serían las configuraciones de las identidades étnico/nacionales, donde los sentidos de lo "boliviano" y lo "chileno" se sitúan como referentes de una tensa dualidad complementaria. De esta forma, se intentará demostrar que las danzas promesantes no solo expresan las identidades colectivas, sino que también las configuran mediante la propia performance.
\end{abstract}

Palabra claves: Danzas promesantes, prácticas rituales, performance, festividades religiosas, identidades colectivas.

This paper inquires on the identity meanings related to the dances performed during the Ayquina's sanctuary fiesta, El Loa Province, Antofagasta Region, Chile. We take on a perspective that emphasizes the ritual singularity of the dances, for then delve into the analysis of some significant supports characteristic of the danced expressiveness - as choreographic patterns, gestures, music and costumes-, through which is proposes the existence of three predominant styles: dances of "old lineage", dances of "local creations", and dances of "recent Bolivian influence". In this sense, one of the most important distinctions would be the configurations of ethno/national identity, where the senses of "boliviano" and "chileno" are positioned as a tensed complementary duality. Thus, we will attempt to show that the dances not only express collective identities, but also configured through the performance itself.

Key words: 'promesante' dances, ritual practices, performance, religious fiestas, collective identities.

\section{Introducción}

La fiesta del santuario de la Virgen Guadalupe de Ayquina, que se desarrolla entre los días 3 y 9 de septiembre de cada año, es la actividad festivoreligiosa de mayor relevancia y figuración al interior de la Provincia de El Loa, Región de Antofagasta, Chile (Figura 1). Igual como ocurre en otros santuarios del norte chileno, en esta festividad coexisten diversas expresiones devocionales, entre las que se encuentra la participación de un gran número de agrupaciones o sociedades de Bailes Religiosos ${ }^{1}$. Centrado específicamente en la experiencia de estas agrupaciones, en el presente trabajo se exploran los significados identitarios que emergen a partir de las performance danzadas. Se considera que las denominadas danzas promesantes constituyen mecanismos simbólicos por medio de las cuales se dan vida y se someten a discusión una serie de significativas categorías socioculturales, estas serían "corporizadas"2 mediante la danza colaborando en la configuración de un denso entramado de significados y distinciones identitarias de orden más general.

Una de las distinciones identitarias centrales que se estructurarían a partir de las performances danzadas de los Bailes Religiosos que participan en la fiesta de Ayquina serían aquellas relacionadas con las identidades étnico/nacionales, donde los sentidos de lo "boliviano" y lo "chileno" se sitúan como referentes de una dualidad tensa pero

\footnotetext{
* Resultados del proyecto de investigación doctoral financiado el Programa CONICYT-Becas Chile (2009-2013).

** Universidad Católica del Norte, Facultad de Humanidades, Antofagasta, Chile. Correo electrónico: jmercado.guerra@ gmail.com.
} 


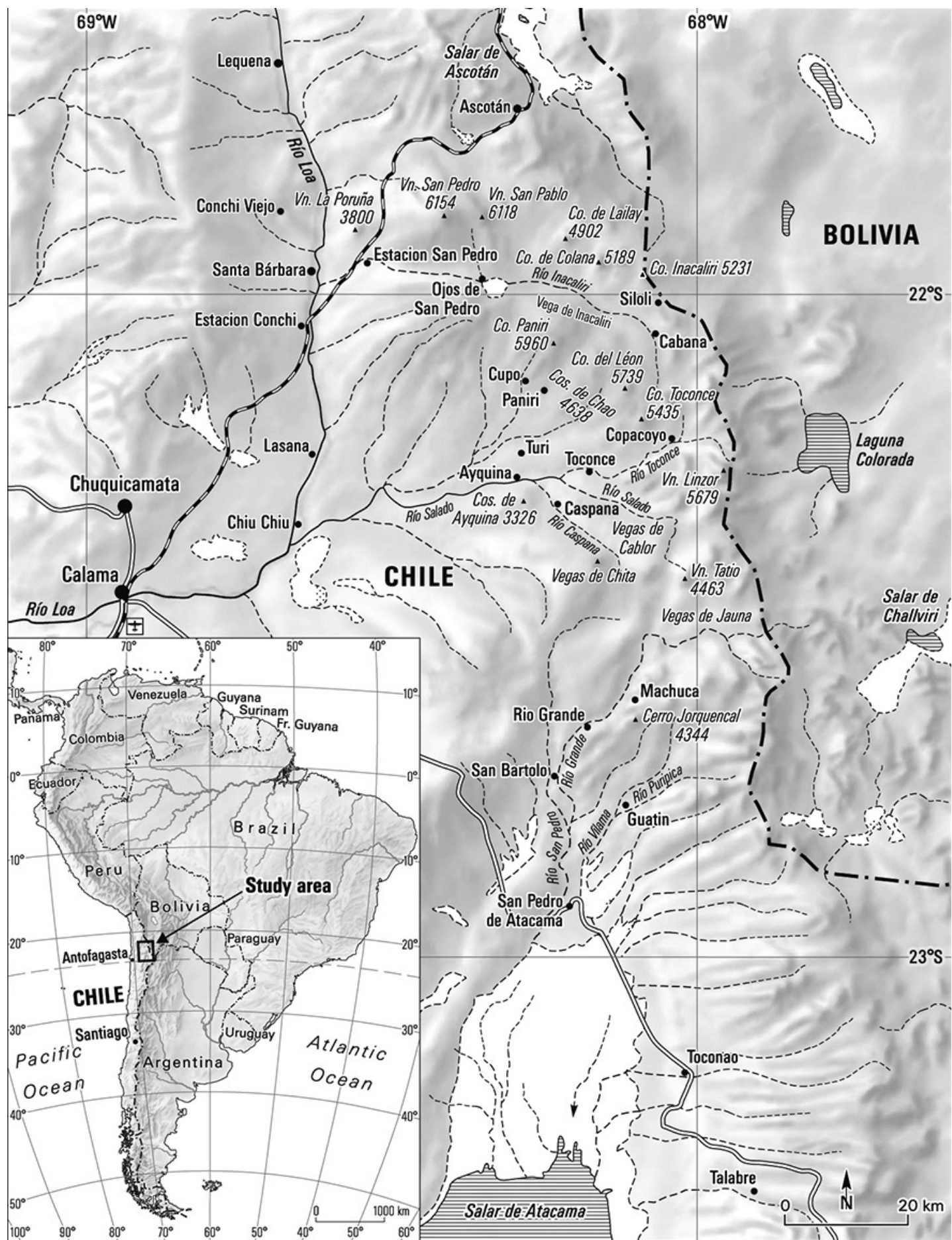

Figura 1. Mapa de la Provincia de El Loa, Región de Antofagasta, Chile. (Castro 2009:84).

complementaria ${ }^{3}$. En este sentido, la problemática que aborda este trabajo tiene relación con evaluar si mediante la ejecución de las danzas promesantes se estaría generando un espacio local de reafirmación, o bien de contestación de dicho dualismo identitario "chileno-boliviano"; un dualismo de 
densidad histórica, el que no ha dejado espacio para comprender y conceptualizar el sentido de mezcla y permeabilidad identitaria entre las poblaciones que habitan hoy la fronteriza provincia de El Loa.

El cuestionamiento que guía la reflexión pretende además introducir nuevos elementos de análisis dentro de una dilatada discusión. Por lo mismo, es necesario destacar que el estudio de los significados de las danzas rituales ha sido un campo de permanente confrontación y negociación en el área cultural andina (Poole 1990; Estenssoro 1992). Durante la época colonial, los eventos religiosos públicos y los dramas danzados surgidos a partir de las relaciones y traspasos entre las tradiciones ibéricas y andinas constituyeron verdaderas exposiciones y reafirmaciones del cuerpo político de la sociedad urbana colonial (Abercrombie 1996). Es así como hay quienes plantean que por los procesos de evangelización se habría producido una cierta homogenización de la práctica ritual danzada, borrando sus señas de identidad regional y posibilitando, al mismo tiempo, el establecimiento de las bases para el surgimiento de nuevas identidades indígenas coloniales (Estenssoro 1992). Hacia el siglo XVIII, muchas de las celebraciones religiosas urbanas se constituyeron en espacios de expresión de los emergentes grupos mestizos, antecedentes directos de la actual cultura "chola" en países como Bolivia y Perú (Abercrombie 1996). Estos antecedentes nos muestran la existencia de una estrecha relación entre el desarrollo histórico del fenómeno de las danzas rituales en los Andes y los procesos de emergencia de nuevos grupos sociales y sus propias dinámicas identitarias.

Resulta evidente que este fenómeno de larga duración, característico de la sociedad colonial andina, ejerció una notable influencia en el surgimiento y posterior desarrollo de las sociedades de Bailes Religiosos en el actual Norte Grande de Chile. Sin embargo, el surgimiento de fraternidades, sociedades o agrupaciones de devotos danzantes en esta zona es un fenómeno algo más tardío en relación con otros lugares de los Andes, porque en el Norte Grande chileno el proceso habría estado más asociado a los ciclos de auge de salitre y cobre entre los siglos XIX y XX (Núñez 2004; González 2006; Díaz y Lanas $2013)^{4}$. Por lo mismo, resulta interesante poder indagar en aquellos signos de identidad presentes específicamente en las danzas promesantes; signos que, puestos en relación con su contexto sociohistórico, han demostrado aportar relevante información, como por ejemplo, acerca de los procesos de "chilenización" en esta zona del norte de Chile (González 2006; Díaz 2009; Díaz y Lanas 2013).

Es así como se puede sostener que los Bailes Religiosos del Norte Grande de Chile surgen como un mecanismo ritual vinculado a determinadas celebraciones marianas, estas experimentaron un notorio crecimiento a partir de los procesos de industrialización minera y de urbanización en puertos y pampas. Entre las principales celebraciones nortinas con características de santuario se pueden mencionar a la fiesta de la Virgen de Las Peñas en Arica (Lavín 1948a, 1948b; Van Kessel 1992a), la fiesta de la Virgen de La Tirana en Tarapacá (Lavín 1950; Uribe 1963; Guerrero 2007; Van Kessel y Tennekes 1986; Martínez 1988; Laan 1993; González 2006; Campos et al. 2009; Díaz 2011; Díaz y Lanas 2013) y, justamente, la fiesta de la Virgen de Ayquina en El Loa (Mostny 1948; Aguirre 1967; Van Kessel 1975; González et al. 2007; Letelier 2010).

Si bien es evidente que existe una gran diversidad de trabajos referidos a los Bailes Religiosos en el Norte Grande chileno, hoy resulta necesario intentar consolidar un enfoque crítico o alternativo que pueda rebatir la primacía que ha tenido el paradigma de la "supervivencia estructural" en el análisis histórico y social de este difundido fenómeno. Dicho paradigma de la "supervivencia" enfatiza en las diferencias existentes entre unas formas culturales cristianas exógenas y un contenido interno subyacente de origen andino prehispánico (Wachtel 1976). Desde esta perspectiva, se sostiene que el pensamiento religioso y la cosmovisión propiamente andina habrían logrado sobrevivir clandestinamente hasta hoy en la expresión ritual de los Bailes Religiosos por debajo de las apariencias dominantes de una estética religiosa mestizo-europea (Van Kessel 1973 y siguientes $)^{5}$. Esta postura impide considerar-como sostenemos en este trabajo- la potencialidad que tienen las danzas promesantes para constituirse en espacios abiertos a la construcción de significados y al moldeamiento permanente de las identidades.

En este sentido, algunas voces críticas -con las que, por cierto, adscribimos- han planteado que las tesis enfocadas en las "supervivencias estructurales" de la cosmovisión andina presentan una imagen ahistórica y formalista de los procesos sociales (Platt 1996). Así mismo, también se ha criticado el hecho de que este tipo de tesis pueden llegar a "sustentar las 
reflexiones neoevangelistas de aquellos sacerdotes contemporáneos que ven con escepticismo la eficacia de los esfuerzos misioneros" (Platt 1996:17). Aun así, en el Norte Grande de Chile pareciera ser que la tesis de Van Kessel continúa siendo influyente (cfr. Gavilán y Carrasco 2009), surgiendo solo en los últimos años algunas perspectivas renovadas que se apoyan principalmente en la difusión de los estudios de la performance (Campos et al. 2009; Campos 2013; Letelier 2010; Chamorro 2013), la etnomusicología (Díaz 2009; Wolf 2012) y las indagaciones históricas (González 2006; Díaz 2011; Díaz et al. 2012; Díaz y Lanas 2013).

Estas nuevas miradas en torno al fenómeno promesante vienen a reactualizar, en el contexto del norte chileno, un debate sobre ciertas formas de cultura expresiva -es decir, músicas, danzas, rituales, teatralizaciones, etc. (Cánepa 2001) - que en otros lugares del centro y sur andino viene desarrollándose con mucha intensidad desde hace varias décadas (Romero 1988; Cánepa 1998, 2001; Mendoza 2000; Abercrombie 1992, 2003, 2006; Cárdenas 2009). Estos últimos estudios dejan en evidencia un creciente interés por revisitar los paradigmas adscritos a las perspectivas de las "supervivencias", planteando algunas interesantes críticas y redefiniciones teóricas que se inscriben, mayoritariamente, en la línea de la antropología de la experiencia y la performance (Cánepa 2001). Rescatando esta genealogía del debate en torno a los fenómenos de danza ritual en los Andes y, más específicamente en el Norte Grande de Chile, el presente trabajo se propone establecer una mirada sobre el caso de los Bailes Religiosos de la fiesta del santuario de Ayquina. Y por medio de este análisis aportar a la consolidación de nuevas perspectivas en torno a este difundido fenómeno sociocultural.

\section{Fases del Ritual Promesante en la Fiesta de Ayquina ${ }^{6}$}

La fiesta "grande" del santuario de Ayquina congrega, según estimaciones de la prensa y las autoridades locales, a 50.000 personas; vale decir, a más de un tercio del total de habitantes de toda la provincia de El Loa. El bailarín o bailarina promesante debe cumplir como requisito con un mínimo de tres asistencias seguidas a la fiesta para dar por acabada su promesa; en sus manos -o bien, en un llamado de la propia Virgen-queda la decisión posterior de continuar participando, o bien retirarse del baile. La preparación anual es en muchas ocasiones costosa y sacrificada; los/ as promesantes deben asistir a diversas reuniones previas, pagar cuotas de dinero para costear las bandas de músicos, las vestimentas, el transporte, el arriendo de los sitios de ensayo, entre otras cosas. Sin embargo, el/la promesante suele realizar con satisfacción todos estos esfuerzos, pues se considera que la Virgen sabrá en su momento recompensar los sacrificios.

A medida que se acerca septiembre se comienzan a intensificar los ensayos, por ello resulta muy común escuchar por las calles de diversas poblaciones de Calama los sonidos de las bandas de bronce, o simplemente bandas de "bombo y caja". A partir del 3 de septiembre los Bailes Religiosos comienzan a realizar su traslado hasta el pueblo de Ayquina, ubicado en la precordillera andina a unos 75 kilómetros al oriente de la ciudad de Calama. La hora de llegada a Ayquina es variable según la propia decisión o grado de organización de cada Baile.

El ritual promesante en la fiesta del santuario de Ayquina puede dividirse en 6 fases principales: la entrada, el saludo, los turnos de baile, la víspera, el alba, la procesión y la despedida. La primera fase (la entrada) es el rito de separación del/la promesante. Cada Baile se reúne a la entrada del pueblo, en el llamado Calvario de Cristo. Ahí se forman en filas paralelas y realizan un canto de saludo a una alta figura de Cristo. El caporal o jefe del Baile expresa su satisfacción por haber llegado un año más a la fiesta, y solicita a Cristo su permiso para entrar al pueblo. El Baile se dirige, posteriormente, hacia la iglesia de Ayquina por la calle principal (Figura 2).

Durante la siguiente fase, el saludo, el Baile hace su ingreso al templo formado en estrictas filas paralelas, una de hombres y otra de mujeres. Adelante va el primer caporal y la portaestandarte, quien carga el símbolo del Baile; esta inclina el estandarte tres veces en dirección a la Virgen y se sitúa a un costado de la imagen de la Virgen. Los promesantes se ponen de rodillas a lo largo del pasillo central de la iglesia, siempre formados en dos filas paralelas (Figura 3). El Baile es recibido al interior de la iglesia por un representante de la comunidad de Ayquina, quien toma la palabra, les da la bienvenida e inicia un canto de alabanza que es secundado por todos/as los/as presentes. El saludo marca el ingreso definitivo del/la promesante a la fiesta religiosa. 


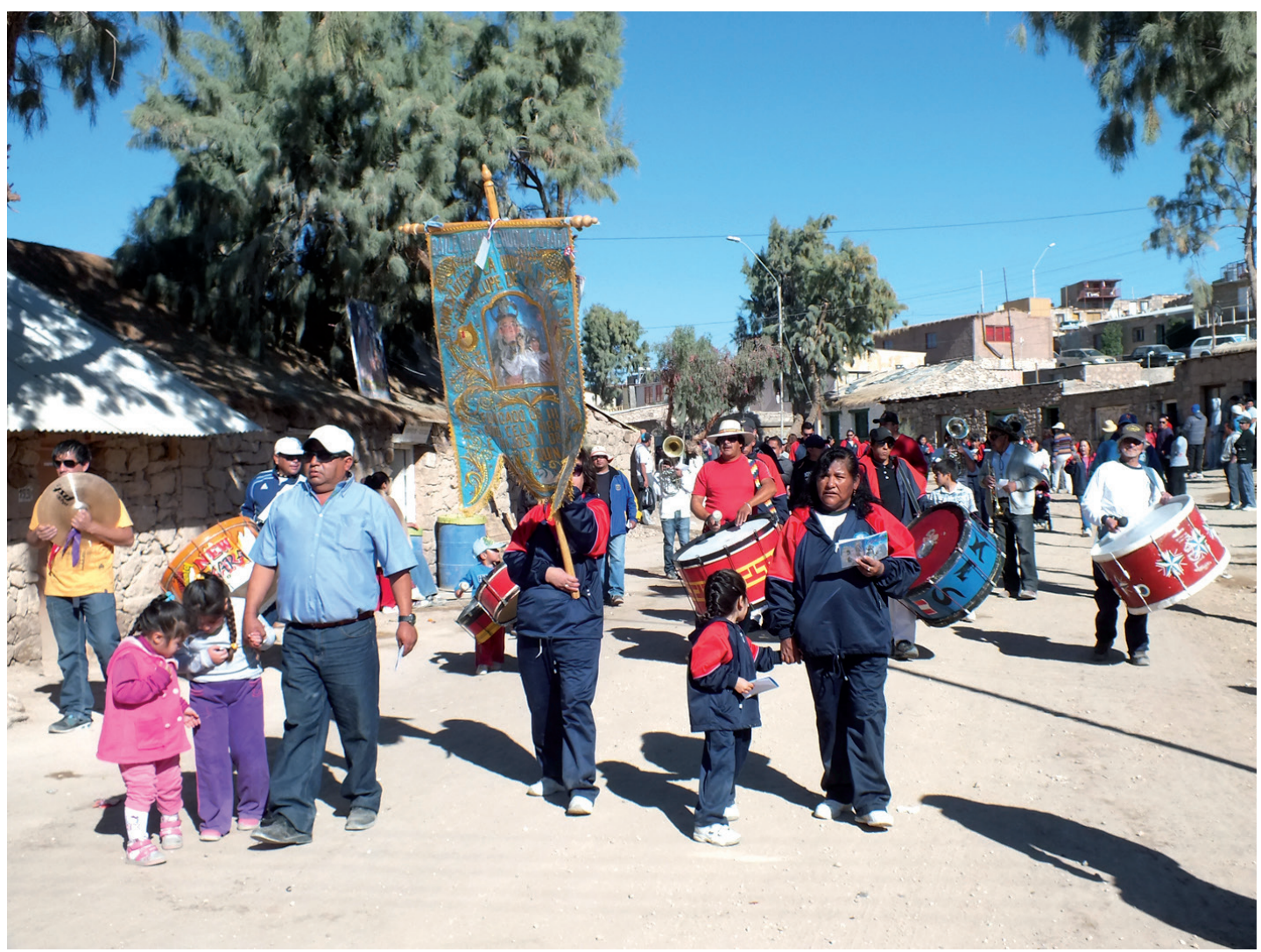

Figura 2. "Entrada", Baile Hindú de Chuquicamata, Ayquina, septiembre 2012. Fotografía del autor.

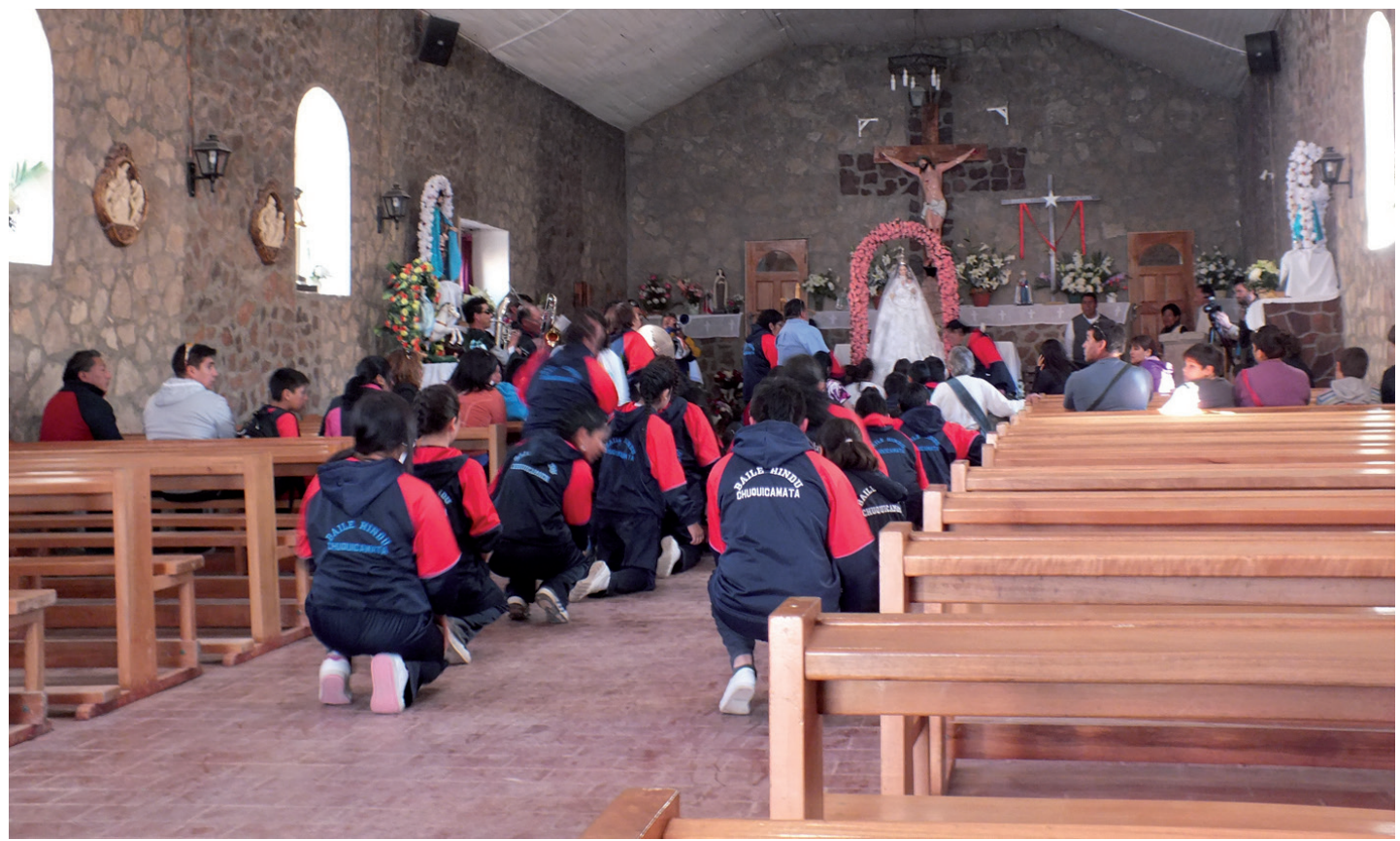

Figura 3. "Saludo", Baile Hindú de Chuquicamata, Ayquina, septiembre 2012. Fotografía del autor. 
A partir del tercer día de fiesta-el 5 de septiembre-comienzan los denominados "turnos de baile"; una actividad fundamental dentro de la dinámica ritual del/la bailarín/a promesante, y que también genera mucha expectación entre otros devotos y curiosos que acuden a la fiesta. Se podría decir que la fiesta "grande"7 del santuario de Ayquina se ha transformado en un verdadero "evento de danza" (Royce 2002), debido a la centralidad que tiene esta expresión en el conjunto de la experiencia promesante. Sin embargo, esta misma noción de "evento de danza" considera que es imposible comprender cabalmente un determinado "evento" sin tener en cuenta la diversidad de elementos contextuales que lo hacen posible.

La mayor parte de los 46 Bailes Religiosos que asisten actualmente a la fiesta del santuario están agrupados en una federación denominada Central de Caporales de Calama. Sin embargo, del total de Bailes asistentes, existen tres que se escindieron de la Central de Caporales en el 2011 para dar vida a una nueva federación: la Asociación de Bailes Religiosos del Santuario de Ayquina. Debido a la enorme cantidad de Bailes Religiosos que danzan en la pequeña plaza del pueblo, las federaciones de Bailes (la Central y la Asociación) han desarrollado un estricto sistema de turnos, donde cada agrupación tiene derecho a danzar cada día durante dos turnos de 25 minutos cada uno. A estos turnos centrales se les suman otros dos turnos secundarios, también de 25 minutos cada uno, estos se llevan a cabo en la denominada "plaza de tierra" situada en la parte posterior de la iglesia.

Debido a que el número de integrantes de cada Baile Religioso es variable, la plaza del pueblo se divide en tres secciones. Los Bailes con menos de 100 integrantes (identificados como Bailes "chicos") ocupan uno de esos tercios. Los Bailes que tienen entre 101 y 150 integrantes ("medianos") ocupan dos tercios de la plaza. Y finalmente, los Bailes que tienen más de 150 integrantes (denominados Bailes "grandes") ocupan la plaza completa. Este cuidadoso y estricto sistema de turnos se lleva a cabo durante tres días seguidos, entre el 5 y el 7 de septiembre. Los turnos se suceden constantemente entre las 8:00 AM y las 5:30 AM, lo que se traduce en una verdadera avalancha de sonidos y una exacerbación visual de colores y movimientos, que en su conjunto producen la extraña sensación de un desorden armónico muy propio de la estética andina actual (Martínez 1988).

El 7 de septiembre, por la tarde-noche, finalizan los turnos de danza y la plaza se comienza a preparar para la víspera. Antes de la medianoche se realiza una larga misa. Los promesantes deben asistir a la plaza, la que está abarrotada de gente. El tránsito por las angostas calles del pueblo se torna dificultoso. Justo a la medianoche la Virgen es sacada de la iglesia y las personas apostadas en la plaza la saludan con sus manos levantadas y pañuelos al viento. Se cantan una serie de himnos: el Himno Nacional, el Adiós al Séptimo de Línea (resabios de los procesos chilenizadores experimentados por muchas fiestas religiosas del norte de Chile), y por último, el muy coreado Himno de Calama.

A partir de las 00:30 del 8 de septiembre, se inicia el Alba. Cada Baile Religioso, según un cuidado organigrama, tiene entre 7 y 21 minutos -según su cantidad de integrantes- para ejecutar un canto de alabanza en la iglesia a los pies de la Virgen. Los cantos se suceden durante toda la madrugada hasta la mañana siguiente, finalizando a las 7:45 AM. Posteriormente, durante la mañana del 8 de septiembre continúan algunos turnos de baile hasta que se da inicio a la misa de "campaña" que finaliza a mediodía. Muchos/as promesantes se muestran algo indiferentes ante la misa; algunos/ as aprovechan esta mañana para reponer energías o dar paseos por otros lugares del pueblo, incluida la feria que se ubica en el sector de la cancha de fútbol.

La procesión se inicia a las 15:00 horas. Curiosamente, esta actividad ha pasado de ocupar un lugar central en la fiesta, a ser una actividad muy poco apreciada entre los/as promesantes, debido a

Tabla 1. Clasificación y distribución de 46 Bailes Religiosos del Santuario de Ayquina

\begin{tabular}{lcccc}
\hline \multicolumn{1}{c}{ Estilo } & Calama & Chuquicamata & Copiapó & Total $=\%$ \\
\hline Antigua estirpe (30'-60') & 7 & 6 & 0 & $13=28$ \\
Creación local (40'-90') & 11 & 3 & 1 & $15=33$ \\
Influencia boliviana reciente (60'-2000') & 18 & 0 & 0 & $18=39$ \\
Total & 36 & 9 & 1 & $46=100$ \\
\hline
\end{tabular}


lo caótica y desorganizada que se ha vuelto en los últimos años. La procesión sale con la imagen de la Virgen de Guadalupe y las otras imágenes tutelares del pueblo, como San Roque y San José, junto a la imagen de San Santiago de Toconce, quien "visita" año a año a la Virgen Guadalupe con ocasión de su fiesta "grande" ". La procesión recorre la parte alta del pueblo, para volver a entrar por el calvario de Cristo en dirección a la plaza del pueblo (Figura 4).

A partir de la medianoche del 8 al 9 de septiembre se inicia la última etapa del ritual promesante. Esta etapa es, posiblemente, una de las más emotivas. Es muy común ver a promesantes emocionados/ as y con profunda tristeza por la finalización de la fiesta. A veces, las intensas emociones pueden conducir incluso a desmayos. La salida del ámbito sagrado es abrupta y lastimosa, pero una vez reintegrado al ámbito profano, el sentimiento del/ la promesante es de alegría y satisfacción por el compromiso cumplido. El ritual cierra un ciclo para abrir otro en la vida de los/as promesantes, quienes estructuran gran parte de su tiempo vital alrededor de las actividades del Baile Religioso.

\section{Los "Turnos de Baile": Performance y Estilos de Danza}

En las fases del ritual promesante en Ayquina los turnos de baile gozan de una evidente centralidad, ya que la danza se establece como el canal privilegiado para establecer una comunicación con la imagen santa. Sin embargo, los turnos de baile también se han transformado progresivamente en instancias definibles dentro del concepto más amplio de "performance" o "performance cultural". $\mathrm{La}$ noción de performance es utilizada, en este caso, para conceptualizar aquellas expresiones rituales o "formas de cultura expresiva" (Cánepa 2001) que reproducen o transforman determinados códigos culturales. De esta forma, "las performances son vistas como prácticas constitutivas de la experiencia social de los actores; no son meramente representativas

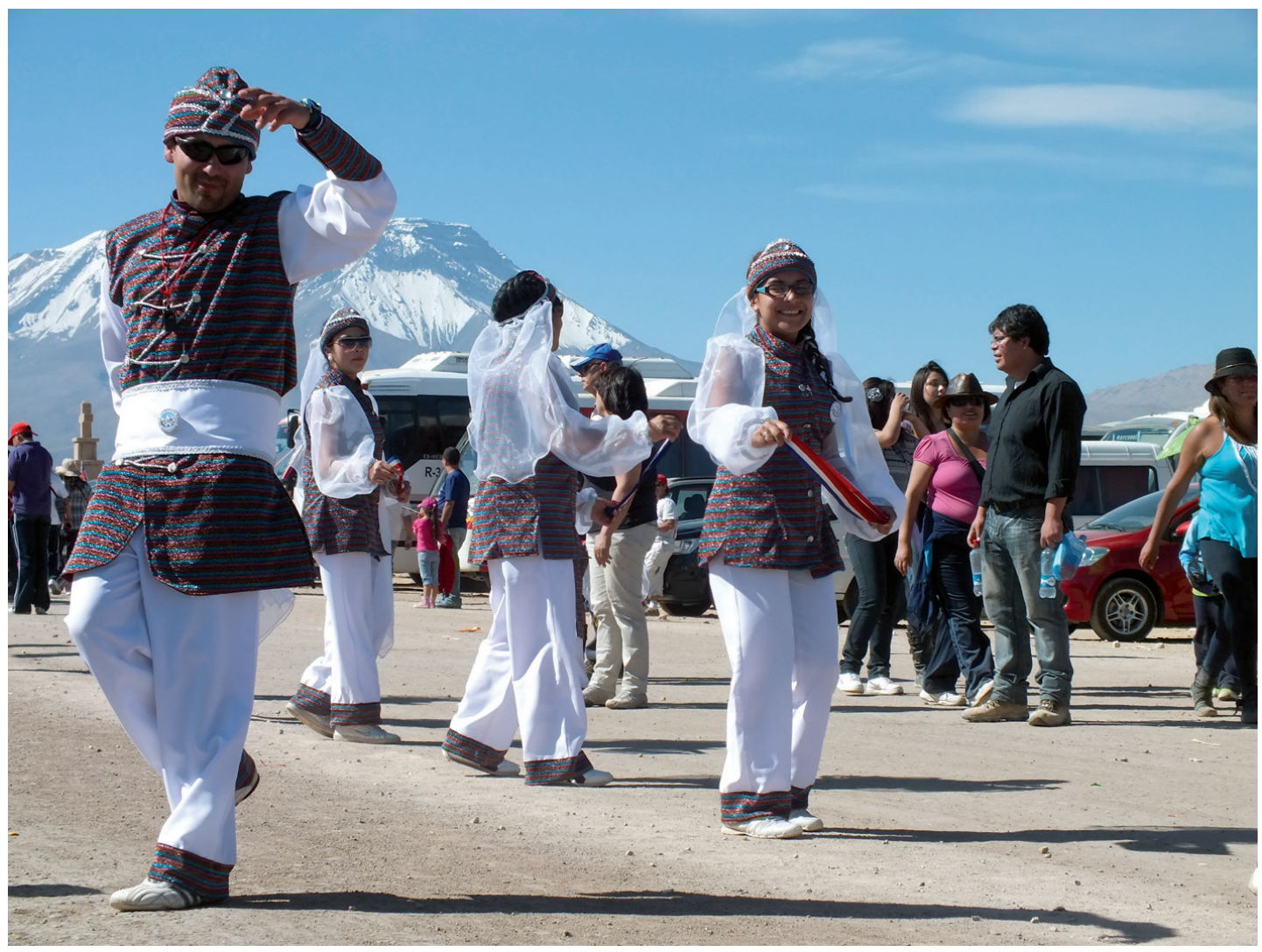

Figura 4. "Procesión", Baile Hindú de Chuquicamata, Ayquina, septiembre 2012. Fotografía del autor. 
de la identidad de un grupo social sino que también contribuyen a construirla" (Citro 2009: 35).

Evidentemente, la perspectiva de análisis planteada por los estudios de la performance introduce un importante giro en la asentada interpretación de las danzas promesantes bajo el paradigma de la "supervivencia", porque dicho paradigma tiende a considerarlas como meros epifenómenos o reflejos de la realidad social. Ahora bien, la consideración de las performances como prácticas constitutivas de los fenómenos socioculturales entraña un dilema fundamental: cómo comprender y conceptualizar aquella ambigüedad intrínseca de un fenómeno performativo, por cuanto no es solo una expresión de significados preestablecidos sino que también es un mecanismo configurador de ellos. Al respecto, se debe comprender que los turnos de baile -así como cualquier otra instancia performativa/corporal-, tienen una potencialidad de disrupción de los habitus (Bourdieu 2012), ello permite abrir un espacio a "disposiciones corporales trasladables"; es decir, un mecanismo que a la vez de expresar los esquemas del habitus, tiene la facultad de generar desplazamientos o disrupciones de los mismos (Jackson 2010). Este aspecto singular es el que deja en evidencia:

la capacidad de las performances para ser utilizadas estratégicamente por diferentes grupos sociales, para crear consenso, legitimidad o disputa de las posiciones de poder. Pueden convertirse entonces en un medio para producir exclusiones o inclusiones sociales, actualizar y legitimar ciertas narrativas míticas o históricas fundacionales y deslegitimar o suprimir otras, para imaginar o crear otras experiencias posibles (Citro 2009: 35).

Antes de adentrarnos en las instancias performativas de los turnos de baile, resulta indispensable proponer una primera clasificación de los tipos o estilos de danzas promesantes presentes en la fiesta del santuario de Ayquina. Esta clasificación tiene solamente una finalidad analítica, aun cuando deja de manifiesto uno de los elementos centrales configurados a partir de la relación entre danzas promesantes y significados identitarios, como lo son las categorizaciones étnico/nacionales ${ }^{10}$.

A partir de un catastro levantado en el 2012 respecto de la totalidad de Bailes Religiosos que se presentan en la fiesta del santuario de Ayquina, podemos considerar que uno de los elementos más significativos a la hora de diferenciar los estilos de danzas promesantes es su origen nacional, especialmente entre aquellas consideradas como "bolivianas" y las consideradas como "chilenas". A modo de ejemplo, Carlos, de la Agrupación Religiosa Tinkus de Ayquina, sostiene de forma explícita esta distinción: "el Baile Piratas de Cristo Rey, ese Baile es chileno. Y después de ese Baile me fui a un awatiri, que ese es boliviano" (entrevista a Carlos 2008). Esta diferenciación dualista de las danzas tiene una sólida presencia en el imaginario promesante, y se instaura como una primera forma de clasificación que remite, evidentemente, al conflictivo emplazamiento de Calama y la provincia de El Loa como espacio de frontera entre lo chileno y lo boliviano.

Es así como asumiendo las significaciones que los/as propios/as promesantes adjudican a las danzas que se ejecutan en el contexto de la fiesta del santuario de Ayquina, se puede establecer la existencia de dos grandes grupos de danzas. En primer lugar, están aquellas danzas que se pueden calificar como "chilenas", dentro de ellas coexisten dos subestilos. Por una parte están aquellas danzas de "antigua estirpe", relacionadas con estilos que provienen de una tradición y técnica corporal presente desde los primeros años de crecimiento de la fiesta del santuario de Ayquina en la década de 1930 (morenos, chunchos, chinos, gitanos, etc., cfr. Mostny 1948) ${ }^{11}$. Del total de Bailes que asisten al santuario de Ayquina, el 28\% ejecuta danzas de este tipo. Por otra parte, pero siempre en este amplio grupo definido como danzas "chilenas", se encuentran aquellas que he denominado como de "creación local"12. Estas danzas introducen ciertas innovaciones gestuales, coreográficas y de vestimenta a las de "antigua estirpe" y es por eso que, a pesar de sus diferencias, se pueden considerar como integrantes de un mismo estilo considerado como "chileno". Las sociedades de Bailes Religiosos que ejecutan este tipo de danzas conforman 33\% del total.

El segundo estilo es aquel identificado por los/as promesantes como danzas "bolivianas", pero que, en este caso en particular, prefiero denominar como danzas de "influencia boliviana reciente". Es un tipo de danza que cuenta con una gran presencia en la fiesta de Ayquina y que se basa en estilos muy populares dentro el área surandina, como son las sayas, las diabladas, las morenadas, los tinkus, etc. Del total de 
agrupaciones presentes en la fiesta del santuario de Ayquina, las que ejecutan este tipo de danzas constituyen $39 \%$ del total. He definido a este tipo de danzas como de "influencia boliviana reciente", para denotar el hecho de que la influencia boliviana ha estado presente en la zona desde el mismo momento en que este territorio -anteriormente boliviano- pasó a formar parte de la soberanía chilena luego de la Guerra del Pacífico (1879-1883). De esta forma, la influencia boliviana debe ser vista como un fenómeno cultural de larga duración, el que remite a una cierta voluntad o tendencia permanente de cierta parte de la población calameña por reivindicarse como perteneciente a la cultura boliviana; sometiendo a discusión, o al menos tensionando, el paradigma de homogeneidad cultural que prima en la ideología nacional chilena.

Un aspecto interesante que surge de esta primera aproximación hacia los estilos de danza es que existe una relativa paridad porcentual entre los diferentes estilos: $28 \%$ son danzas de antigua estirpe, $33 \%$ son de creación local y $39 \%$ son de influencia boliviana reciente. Sin embargo, si comparamos los estilos de danza presentes en el conjunto de las celebraciones religiosas en la comuna de Calama (incluyendo festividades patronales en pueblos como Caspana, Toconce, Conchi Viejo, Cupo, entre otras), podremos ver que existe una clara preeminencia de aquellas danzas que pueden considerarse como de influencia boliviana reciente.

Este dato resulta muy ilustrativo para comenzar a vislumbrar la forma en que las danzas promesantes son asumidas como referentes de identidad por quienes las ejecutan, ya que la presencia mayoritaria de danzas de influencia boliviana reciente en las festividades patronales de pueblo pareciera ser un indicador de la relación que existe entre este tipo de danzas y los fenómenos de emergencia de la etnicidad o etnogénesis lican antai o quechua en la zona, según sea el caso (cfr. Gundermann 2003, 2004). Por el contrario, en el caso de la fiesta del santuario de Ayquina, existe una preeminencia de los estilos "chilenos" representados por las danzas de antigua estirpe y de creación local; asunto que parece tener relación con las características masivas de la festividad y la injerencia que tienen un cierto tipo de promesantes que no mantienen necesariamente relaciones con las comunidades indígenas.

Esta propuesta de clasificación constituye, evidentemente, un vehículo de entrada al tema de las significaciones culturales e identitarias atribuidas a las danzas promesantes. En ningún caso puede considerarse como una delimitación estática, ni mucho menos definitiva. Por el contrario, esta clasificación de estilos de danza en la fiesta de Ayquina constituye una estrategia metodológica destinada a alcanzar una selección más precisa de los casos de estudios. Es así como, si bien se trabajó en el registro y descripción densa de 10 turnos de baile ejecutados por diferentes agrupaciones, se ha optado por priorizar el abordaje de dos casos representativos de los principales estilos de danza identificados. Concretamente, los casos a abordar son los del Baile Hindú de Chuquicamata y el Baile Reyes de la Tuntuna de Calama ${ }^{13}$. El primero de estos Bailes ejecuta un tipo de danza enmarcada en lo que podríamos denominar como una creación local -propia del Norte Grande de Chile-, pero que al mismo tiempo se encuentra plenamente adaptada a lo que se puede considerar como las danzas promesantes de antigua estirpe. Por otro lado, el caso del Baile Reyes de la Tuntuna puede inscribirse dentro del conjunto de agrupaciones que ejecutan danzas de influencia boliviana reciente, estas establecen una serie de diferencias estéticas con las danzas promesantes más tradicionales, ya sean de antigua estirpe o de creación local. Indagando en ambos casos podremos ir clarificando aquellos elementos expresivos (vestimentas, músicas, coreografías y gestualidades) que permiten reafirmar o poner en tensión los significados identitarios atribuidos a las danzas promesantes.

\section{Humildad, Disciplina y Tradición: El Baile Religioso Hindú de Chuquicamata ${ }^{14}$}

El turno del Baile Hindú se inicia con una formación de dos filas paralelas, compuestas por diez parejas, una fila de mujeres a la derecha y otra fila de hombres a la izquierda (Figura 5). Se inicia la danza con el llamado "primer paso", que se marca a partir del típico ritmo promesante llamado comúnmente como "dos por tres": ritmo en compás de $4 / 4$, distribuido en dos negras, dos corcheas y una negra. Igual que la mayoría de aquellos Bailes de "antigua estirpe" y de "creación local", la musicalidad de la danza se sustenta en patrones rítmicos binarios. Los trajes utilizados suelen ser muy simples y de bajo costo, estos -este caso específico- son confeccionados por la tercera caporala del Baile, quien tiene conocimientos de costura. También existe un sistema de donación de trajes para que así, cuando 


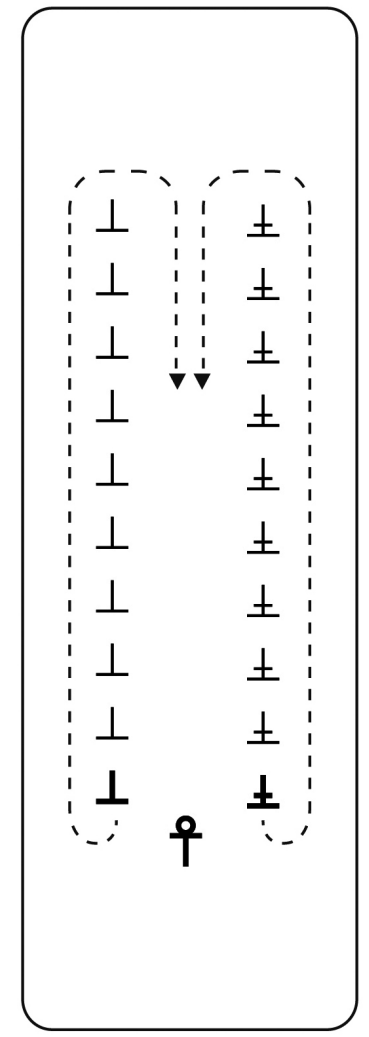

Figura 5. Patrón Coreográfico, Baile Hindú de Chuquicamata. llega un nuevo integrante, este pueda utilizar el traje dejado por algún integrante ya retirado y evitar el gasto que implica la elaboración de trajes nuevos.

El caporal dirige la danza situado en la parte central y superior de rectángulo que constituye un tercio de la plaza; limitado espacio que le corresponde a un Baile considerado "chico". Ambas filas de bailarines/as van avanzando hacia la cabecera, en dirección a la iglesia donde se encuentra la imagen de la Virgen, ejecutando el "primer paso". Llegados hombres y mujeres frente al caporal, se miran de frente y luego giran para trasladarse hacia la parte posterior de la fila ${ }^{15}$. Los punteros -o líderes de cada fila- comienzan a dar la vuelta por la zona posterior o "por afuera", para así volver a situarse en el orden inicial al fondo de la plaza; movimiento que es secundado por toda la fila. El caporal llega frente a ellos realizando el "paso de salto", gira en dirección a la iglesia y avanza continuando muy enfático, siendo seguido por el resto de bailarines/ as. La escena se torna evidente: el caporal ha "mostrado" el nuevo paso a sus bailarines/as y, al mismo tiempo, los ha "ido a buscar" al fondo de la plaza. Los/as bailarines/as siguen a su caporal en dirección a la iglesia. La figura coreográfica asemeja a una breve peregrinación dirigida hacia la Virgen (Figura 6).

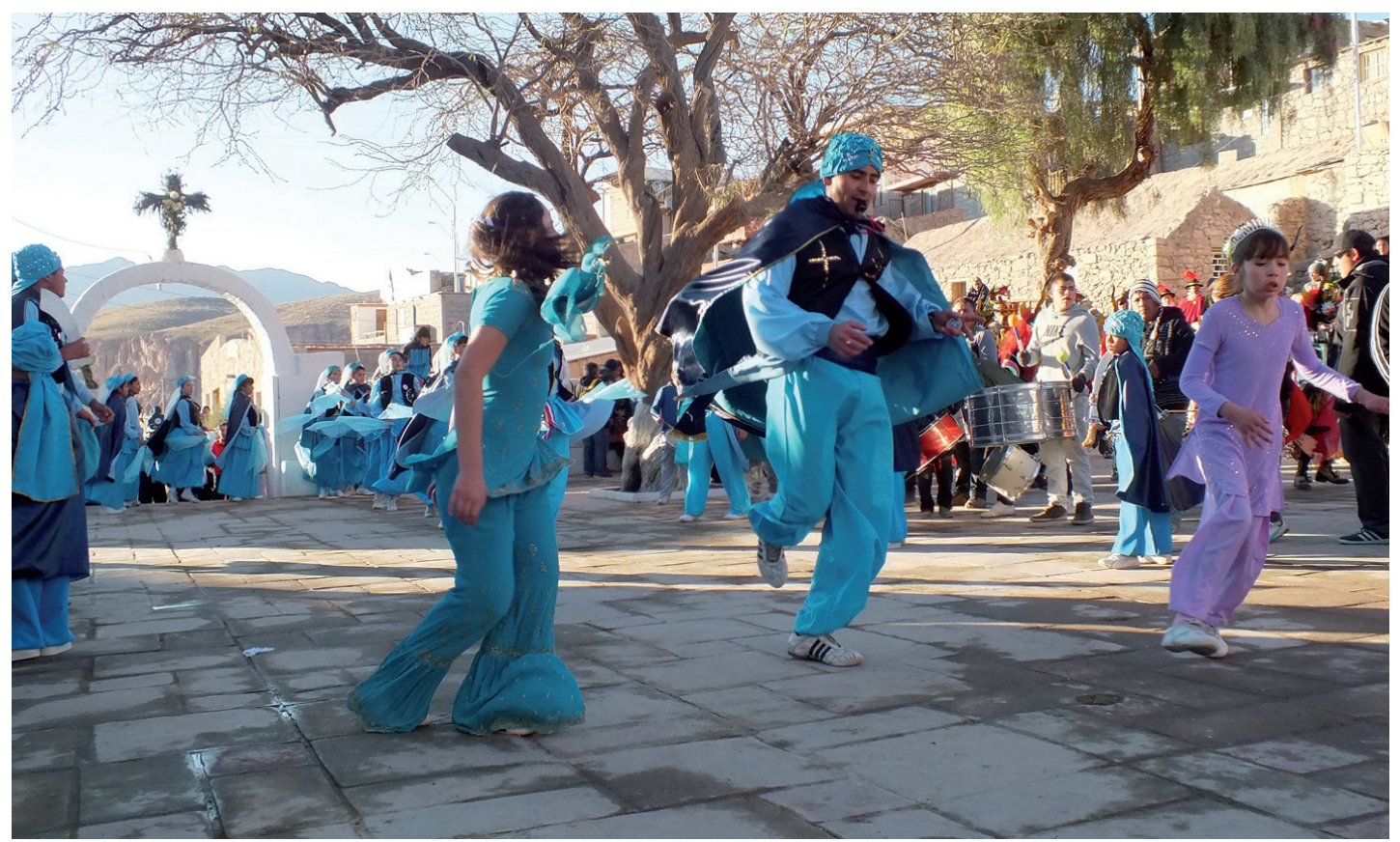

Figura 6. Caporal, Baile Hindú de Chuquicamata, Ayquina, septiembre 2012. Fotografía del autor. 
Las figuras coreográficas o mudanzas se van repitiendo una y otra vez, basadas en el mismo patrón coreográfico, pero incorporando diversos elementos ornamentales como la toma cruzada de una cinta tricolor que llevan las mujeres, o el movimiento de la "cimitarra" (espada de madera) que llevan los hombres. Llegando a la mitad del turno de danza, se comienza a ejecutar el "segundo paso". Este, a diferencia del primero, es un paso de mayor nivel de complejidad, ya que al ejecutarlo se genera un contratiempo de los pasos con el toque del bombo.

Durante los últimos minutos del turno el Baile Hindú introduce una innovación coreográfica muy significativa. Las parejas formadas en filas paralelas se desestructuran. Las mujeres se comienzan a formar en línea de tres y los hombres, ubicados detrás del bloque de mujeres, se comienzan a formar en dos filas paralelas. Conformados en estos dos bloques o escuadrones, cambian el segundo paso por el primero y comienzan una secuencia de figuras diferenciadas entre hombres y mujeres (Figura 7). Esta variación coreográfica tiene que ver con una cierta concepción dialógica en la construcción del leguaje danzado. En este sentido, uno de los caporales del Baile Hindú comenta lo siguiente respecto de la creación de esta nueva mudanza:

es como un momento que bailan otros Bailes como los tinkus, las diabladas, los sambos, que ellos bailan por escuadrones; pero los Bailes como el mío, nosotros bailamos por parejas, por filas, no por escuadrones. Entonces quisimos sacar una mudanza nueva, pero que reflejara, no sé, lo que hacían otros Bailes. No es por copiarlos ni nada, sino para modificar y hacer algo nuevo (entrevista a Moisés 2012).

La incorporación de esta nueva mudanza indica la existencia de un lenguaje coreográfico centrado en un diálogo tensionado entre los patrones llamados de "filas paralelas" y los de "bloques o escuadrones". Este aspecto se transforma en un elemento clave en la construcción de los sentidos identitarios por medio de la danza, ya que establece un evidente diálogo con el patrón coreográfico de los Bailes de influencia boliviana reciente; lo que podrá comprenderse de mejor forma a partir del contraste con el segundo ejemplo que

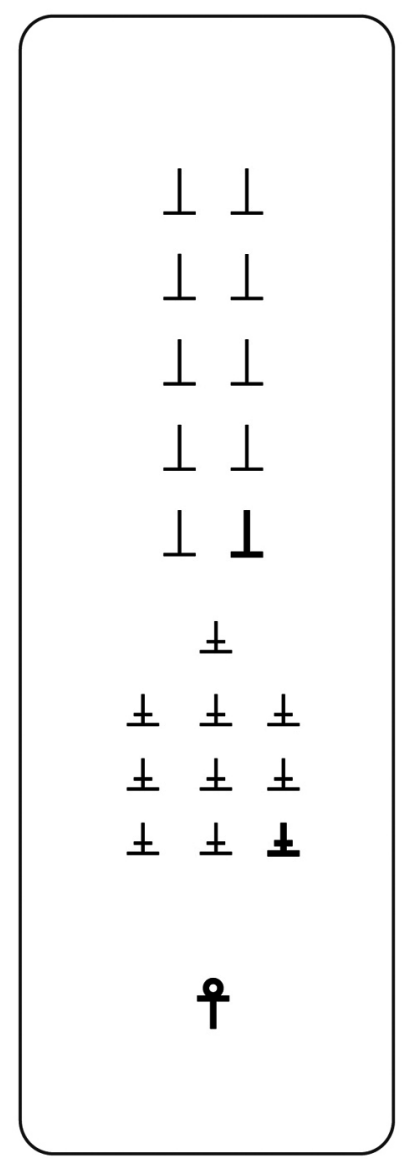

Figura 7. "Mudanza" en bloque o escuadrón, Baile Hindú de Chuquicamata.

abordaremos más adelante. Hacia el final del turno, los/as bailarines/as se vuelven a formar en dos filas paralelas de hombres y mujeres, para luego iniciar su retirada de la plaza.

La performance danzada del Baile Hindú pone en escena y a la vez tensiona ciertas categorías socioculturales de orden general. Una de ellas es la categoría de "humildad"; un término que dentro de la concepción promesante está relacionado con una carencia de recursos económicos o un bajo estatus social. De esta forma, se suele considerar que un Baile es "humilde" cuando no tiene una banda de músicos numerosa, cuando tiene pocos integrantes, o bien cuando no cuenta con trajes vistosos o de compleja y costosa elaboración. Es así como, en primera instancia, los Bailes "humildes" -término asociado también a la noción de Baile "chico"-, parecen remitir a una cierta distinción de clase o 
estatus social. Los/as promesantes reconocen la existencia de este tipo de Bailes a partir de determinados elementos expresivos, lo que permite establecer una cierta relación con el estatus socioeconómico de quienes pertenecen a dicho Baile. Pero mirado desde otra perspectiva, la danza promesante puede transformarse no solo en una expresión del estatus social de sus integrantes sino que también en un vehículo de movilidad social, pues mediante la modificación de algunos elementos expresivos se puede llegar a representar la idea de un mayor poder adquisitivo, e incluso llegar a alcanzar un mayor prestigio social en el contexto del mundo promesante.

Por otra parte, también puede suceder que aquellos Bailes calificados como "humildes" establezcan una resignificación de aquellos elementos que los sitúan en la parte baja del escalafón social del mundo promesante. En este proceso juegan un papel relevante las nociones de "disciplina" y "tradición familiar". En el caso específico del Baile Hindú muchos/as de sus promesantes asumen que son un Baile "chico", pero a la vez saben que gozan de un prestigio único debido a la rigurosa disciplina impuesta especialmente por su primer caporal. Aquella disciplina se pone en evidencia en la puntualidad o en el cumplimiento estricto de la normativa impuesta por la Central de Caporales; pero también parece ser un habitus o una "disposición corporal trasladable" desde el ámbito cotidiano hacia la expresividad danzada y viceversa. En la revisión y análisis de los elementos corporales de la danza del Baile Hindú se deja en evidencia una cierta expresividad corporal rígida, con recurrentes inclinaciones de torsos que remiten a una sumisión del/la promesante ante la imagen de la Virgen (Figura 8). Este tipo de expresividades corporales, que aluden a la rigidez y la disciplina, están muy presentes entre aquellos Bailes considerados como "chicos" y "humildes"; los que, sin embargo, revierten el sentido peyorativo de dichas categorías, señalando que sus Bailes son más "puros" en cuanto a su demostración de fe, entre otras cosas, porque el gasto monetario que realizan para bailar es menor en relación con otro tipo de Bailes. Alberto, primer caporal del Hindú, señala:

los Bailes chicos somos todos uno, si no tenimos [sic] bailarines nuevos es porque a nuestra juventud le gustan otros Bailes..., no voy a decir lujosos, no, nada, porque ellos son dueños... si la manera de mostrar su cariño a la Virgen es así; pero cambian de traje todos los días y son muy costosos (entrevista a Alberto 2012).

La crítica al desmedido gasto económico está siempre latente entre muchos/as promesantes que pertenecen a los Bailes considerados "chicos" o "humiles"; y coincidentemente, la mayor parte de los Bailes considerados bajo estas categorías suelen ser aquellos que se ha denominado como de antigua estirpe o de creación local. A modo de ejemplo, Leonel, segundo caporal del "humilde" y familiar Baile Promesante Los Salteños (un Baile de creación local al igual que el Hindú), señala respecto del desmedido gasto en la contratación de músicos, que:

hay Bailes que están pagando sobre los 10 millones de pesos por una banda, entonces es mucho y no representa para nada el sentido de nuestra fe. O sea, podemos estar en Ayquina y en bandas solamente deben gastarse unos 40 millones de pesos

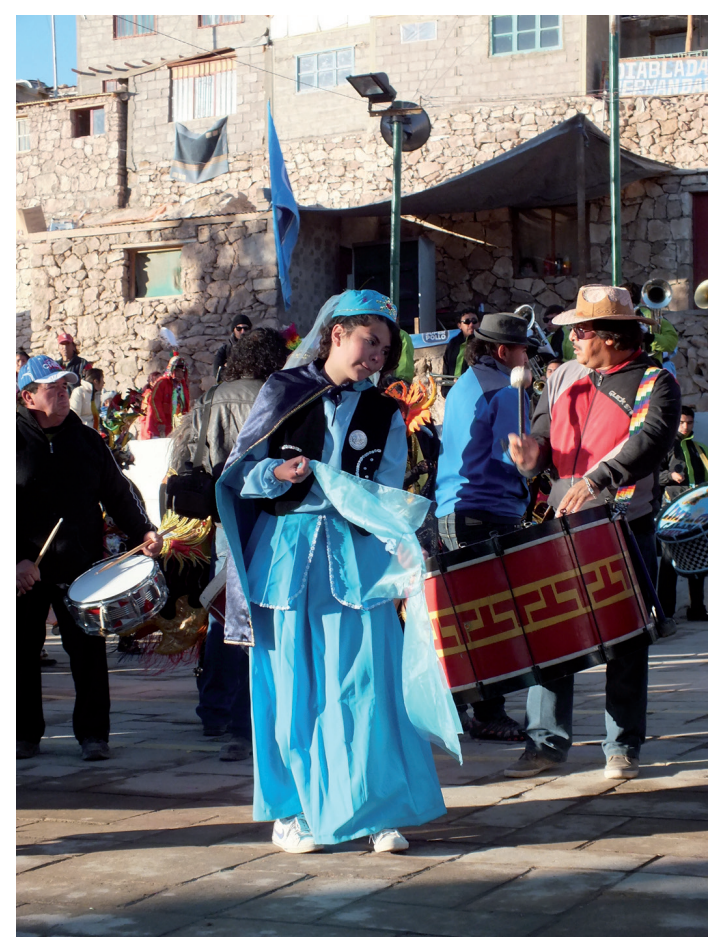

Figura 8. Bailarina promesante, Baile Hindú de Chuquicamata, Ayquina, septiembre 2012. Fotografía del autor. 
con todos los Bailes. Esos 40 millones de pesos, de forma cristiana, pueden servir pa' la Iglesia, pueden servir pa' los pobres, pa' los ancianos [...] no puede ser que el lucro esté invadiendo también la fe (entrevista a Leonel 2012).

Como se aprecia, si bien existen elementos que permiten considerar a los Bailes "chicos" y "humildes" como agrupaciones que presentan ciertas carencias en la forma de llevar a cabo sus performances; los/as promesantes que participan de este tipo de agrupaciones reivindican su pertenencia, señalando que la forma de experimentar la fiesta de manera austera es una forma más cristiana y por lo mismo más correcta que enfatizar en el gasto monetario excesivo, el que se considera como un lujo innecesario. También es posible advertir que esta austeridad o actitud ascética incide en la propia expresividad coreográfica y corporal, porque este tipo de agrupaciones suelen enfatizar en la solemnidad y las gestualidades rígidas y bien normadas.

Otro elemento importante dentro de la revalorización que realizan los/as promesantes pertenecientes a Bailes "chicos" o "humildes" es la reivindicación de una tradición familiar ligada a este tipo de agrupaciones. De ahí que muchos de estos Bailes estén conformados casi exclusivamente por grupos familiares o de estrechas amistades, ello implica que al momento de la elección de un Baile Religioso, los/as jóvenes promesantes ligados a estas familias opten o se les imponga la idea de continuar con la tradición familiar.

Finalmente, resulta necesario reflexionar respecto del tipo de relación que el/la promesante establece con aquello que se representa mediante la danza. La reflexión en este ámbito parece ser un elemento fundamental a la hora de indagar en la relación entre las danzas promesantes y los procesos de configuración de las identidades colectivas. Si seguimos la distinción planteada por Spivak (2009) respecto del significante "representación" ${ }^{16}$, se puede señalar que quienes ejecutan este tipo de danzas ponen en escena una "representación" en el sentido de que no asumen una vinculación directa o emocional con los personajes a los que alude la danza. De ahí que los Bailes de antigua estirpe y especialmente los de creación local suelen adoptar personajes y nombres tan diversos, disímiles y lejanos como hindúes, pieles rojas, piratas, españoles, mexicanos, samurai, vaqueros, marinos, etcétera.
La vinculación con lo representado, en estos casos, no pareciera tener relación con una voluntad de "representar" en un sentido político del término, sino que más bien con la idea de poner en escena una personificación externa a la propia identidad y al cuerpo promesante; en otras palabras, se pone en escena una relación de alteridad con lo representado. Este aspecto resulta fundamental para la comparación entre las danzas consideradas "chilenas" (de antigua estirpe y de creación local) con aquellas que se ha denominado como de "influencia boliviana reciente"; ya que estas últimas -como veremos en seguida- parecen aludir a un tipo de vinculación más directa con lo representado.

\section{Sensualidad, Juventud y "Bolivianidad": El Baile Religioso Reyes de la Tuntuna ${ }^{17}$}

El Baile Reyes de la Tuntuna, a diferencia del Baile Hindú, es una agrupación que cuenta con una buena cantidad de promesantes, muchos/as de los/as cuales son jóvenes atraídos/as por la vistosa expresividad musical y gestual de la danza. Es un Baile considerado como relativamente grande, ya que cuenta con el número suficiente de promesantes para ocupar dos tercios de la plaza durante sus turnos de baile. Los Reyes de la Tuntuna, además, han adquirido un alto grado de prestigio en el contexto de la fiesta, tanto por las vistosas innovaciones coreográficas que han introducido en los últimos años, como también debido a que su primer caporal es el presidente de la Central de Caporales.

El primer elemento expresivo a destacar del turno de baile de los Reyes de la Tuntuna es que su patrón coreográfico se sustenta en bloques o escuadrones (Figura 9), lo que establece una clara diferencia con Bailes más pequeños, como el Hindú, que utilizan regularmente el patrón de filas paralelas. El turno de los Reyes de la Tuntuna comienza con la banda de bronce instalada en la plaza, ante ella los/as bailarines/as entran marcando el paso y divididos en cinco bloques. Por el costado izquierdo de la plaza ingresan tres bloques: uno de mujeres, otro de hombres y un bloque mixto. Al mismo tiempo, pero desde el arco de la entrada principal, hace su ingreso un bloque de hombres y otro de mujeres.

El caporal se instala en el centro y da sus indicaciones tocando el silbato tres veces. El ingreso de los/as bailarines/as se ve, a la distancia, ciertamente caótico. Los bloques ingresan marcando el paso normal, el que es similar para 


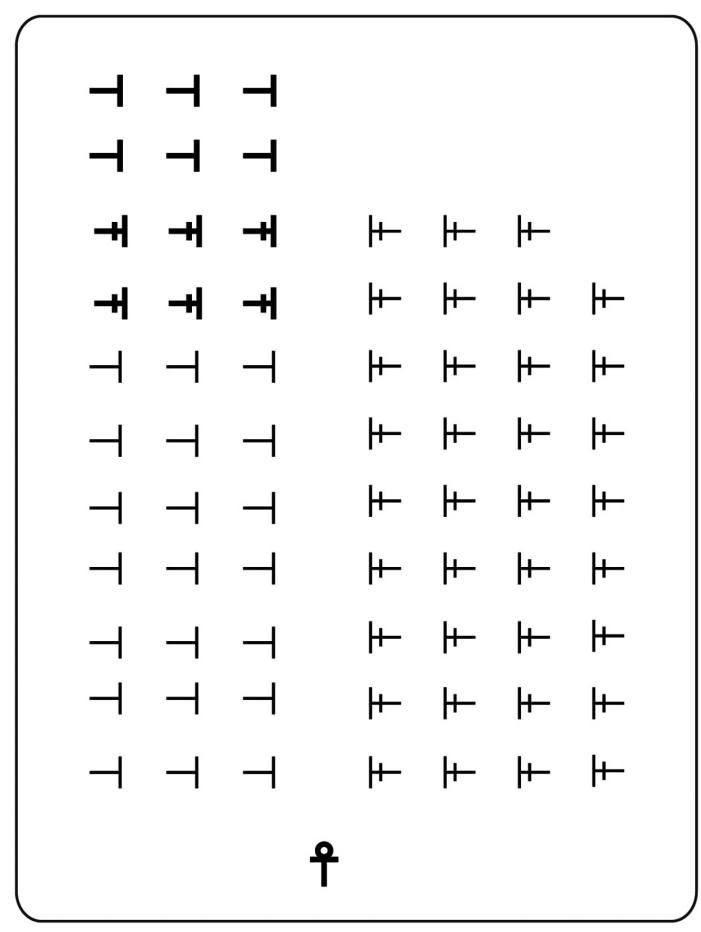

Figura 9. Patrón coreográfico, Baile Reyes de la Tuntuna.

hombres y mujeres: se marcan dos tiempos con el pie derecho pegando en el suelo; luego, con el izquierdo, se marcan otros dos tiempos pero con menos fuerza que los tiempos anteriores. Entre los cambios de pie hay pequeños silencios que son, precisamente, el elemento que permite dar forma al patrón rítmico sincopado que caracteriza a estos ritmos de saya ${ }^{18}$.

A los pasos mencionados se le agregan sinuosos movimientos de hombros, estos se ejecutan en sentido contrario al golpeteo de los pies en el suelo. En el movimiento de los hombros, así como también en el modo de ejecución de los pasos, hay claras diferencias entre hombres y mujeres. Los hombres realizan los pasos con mayor énfasis; flexionan más las rodillas para golpear el suelo con fuerza. Los hombros se menean con rigidez; uno de ellos se levanta mientras el otro se baja levemente, y luego se realiza el mismo movimiento con el hombro contrario. Este movimiento se ve reforzado por unas anchas hombreras, así como también por el sonido metálico de los cascabeles que cuelgan de las botas. Las manos van seguras en los costados, un poco adelantadas acompañando el movimiento de los hombros. Las gestualidades y vestuarios de los hombres parecieran reforzar la idea de un cierto vigor masculino.

Por su parte, las mujeres ejecutan el mismo paso que los hombres pero con algunas relevantes modificaciones. El movimiento de los hombros es mucho más sutil, y se acompaña de un suave y flexible movimiento de manos, las que van adelantadas más arriba de la cintura. Con el movimiento de las manos y los dedos, pareciera que las mujeres van tejiendo imaginariamente con suaves toques al viento (Figura 10). El movimiento de los pies no incluye una flexión de rodillas -como ocurre en el caso de los hombres-, sino que más bien se acompaña de un movimiento de caderas, también sutil pero suficiente como para generar un amplio movimiento de la pollera de lado a lado.

A indicación del caporal, y mientras los/as bailarines/as todavía se están desplazando dentro de la plaza para tomar su ubicación, los hombres comienzan a ejecutar el mismo paso inicial pero incorporándole saltos y giros. Las mujeres, sin realizar saltos, ejecutan los giros de manera sincronizada con los hombres. Finalmente, los bailarines/as logran distribuirse a lo largo de la plaza formando una figura de "equis" o "cruz" (Figura 11). En esa posición, todos/as los/as promesante se inclinan y se persignan en dirección a la iglesia donde se encuentra la venerada "Chinita" (apelativo cariñoso que se le da a la Virgen). La música se silencia por algunos segundos, para luego volver a todo volumen. Los/ as bailarines/as se ponen de pie. Las mujeres -excepto las que integran el bloque mixto- se toman de la cintura. Cuando ya están todos ubicados en sus posiciones iniciales, la "cruz" comienza a girar formando una especie de "hélice" en movimiento.

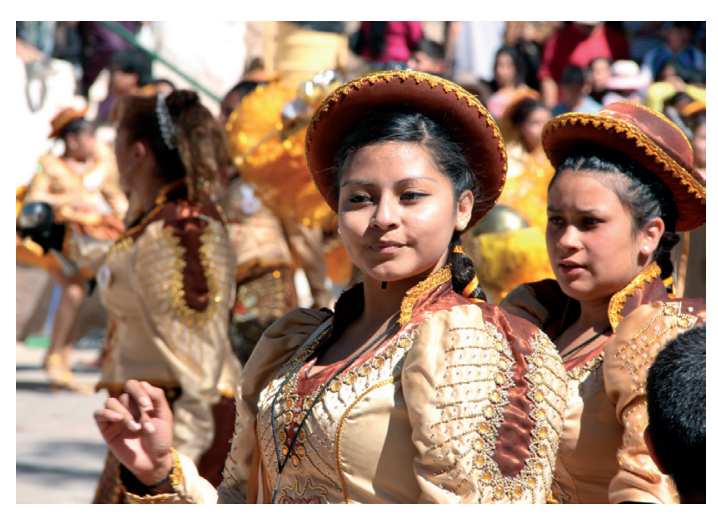

Figura 10. Bailarina promesante, Baile Reyes de la Tuntuna, Ayquina, septiembre 2012. Fotografía de Max Ropert. 


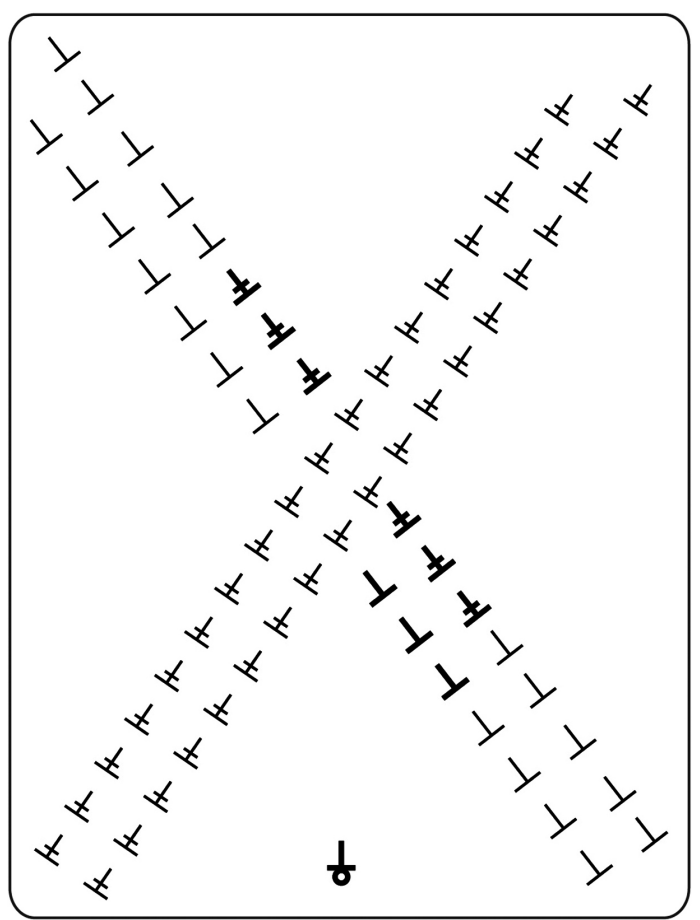

Figura 11. Figura coreográfica "Cruz".

Las mujeres, siempre tomadas por la cintura, comienzan a ejecutar unos pasos cortos de lado a lado. Los hombres, por su parte, van sueltos realizando el mismo paso pero incorporando vigorosos saltos. En esta figura coreográfica el contraste hombre/ mujer es todavía más acentuado: los hombres van realizando enérgicos saltos y gritando "; hey, hey!; ¡hey, hey!"; las mujeres tomadas de sus cinturas se limitan a emitir con voz aguda y reiteradamente "eeeso, eeeso...".

El tema de la sensualidad se ha sido incorporado a las danzas promesantes, justamente, a partir de la mayor presencia adquirida por aquellas agrupaciones que cuentan con una influencia boliviana reciente. En el caso del Baile Reyes de la Tuntuna, podemos observar que los movimientos corporales de hombros y caderas constituyen elementos de juicio sobre los que se expresan evaluaciones respecto de los grados de sensualidad presentes en la danza. De igual forma, y desde la perspectiva del/ la promesante, dichas gestualidades se transforman en una evidente corporización (Csordas 2010) de las categorías hegemónicas de sexo/género. Aun así, cabe destacar que este mismo fenómeno de corporización abre un espacio para la introducción de elementos disruptivos en el habitus promesante más tradicional, el que tiende a comprender a la danza como un espacio abierto principalmente a la corporización de los valores éticos relacionados con la disciplina y la austeridad, como se pudo evidenciar en el caso del Baile Hindú.

En medio de esta suerte de juego de tensión entre la sensualidad y la austeridad, la brecha generacional se comienza situar como un elemento catalizador de la problemática. Por una parte, los sectores mayoritariamente juveniles comprenden a la danza promesante como un mecanismo lúdico y abierto a la construcción y expresión de sus categorías de sexo/género. Por otra parte, los sectores más tradicionalistas y mayoritariamente adultos comprenden a la danza promesante como un mecanismo de expresión únicamente ligado a la veneración de la imagen santa, y por lo tanto, determinado por las muestras de disciplina y austeridad. En definitiva, se puede advertir cómo a partir de ciertos elementos relacionados, entre otras cosas, con la expresividad gestual de la danza se van configurando ciertos entramados de significación entre los promesantes; entramados que, en este caso en concreto, tienen que ver con la sensualidad y la construcción de las categorías de sexo/género, así como también con la tensión implicada en la brecha generacional entre segmentos promesantes juveniles y adultos.

Por otra parte, en esta danza también emerge el tema de la presencia y consolidación de lo "boliviano". Un elemento altamente significativo es que las agrupaciones que interpretan este tipo de danzas suelen ser aquellas que además cuentan con mayor cantidad de promesantes en sus filas. En este caso, podemos establecer que existe una directa relación entre los aspectos simbólicos que definen a los Bailes "grandes" (mayores recursos, mejor calidad en la performance, pero sin embargo una eventual despreocupación por los elementos propiamente litúrgicos) con aquellos que definen a una determinada danza como "boliviana".

La denominación de danza "boliviana" construida por los/as propios/as promesantes juega un papel preponderante a la hora de explorar las posibles relaciones entre las danzas promesantes y los procesos de construcción de las identidades colectivas, o en este caso, identidades étnico/ nacionales. A diferencia de lo que ocurre en otros lugares de los Andes, como en Chile central o el Perú, donde lo "boliviano" es mirado con ciertos aires de desprecio; en el caso de ciertos Bailes calameños que asisten a la fiesta de Ayquina existe 
una evidente resignificación y valorización de los elementos comprendidos como "bolivianos". A modo de ejemplo, podemos señalar que los integrantes del Baile Tinkus, una de las agrupaciones más populares en la fiesta de Ayquina, y que además ejecuta una danza de reconocido origen boliviano, señalan orgullosamente que "nosotros tenemos todo, todo, el cien por ciento de las cosas que nosotros tenemos es boliviano. No hay nada que se haga, de las cosas que tenemos, que se haga acá en Chile" (entrevista a Carlos 2008).

Siguiendo la misma idea de valorización de los elementos propiamente bolivianos, el mismo integrante del Baile indica que:

específicamente Calama, ni siquiera Iquique, ni siquiera Arica, ni siquiera Antofagasta; Calama es la única ciudad que tiene Bailes Religiosos que son originales de Bolivia, originales al cien por ciento. Porque si tú comparai', por ejemplo, este Tinku que nosotros tenemos aquí, cuando fue creado, fue hecho a regla, fue creado así. Pedimos autorización al consulado boliviano (entrevista a Carlos 2008).

Resulta evidente que esta construcción identitaria está determinada por los límites de la alteridad impuestos por otros Bailes que son considerados como "chilenos". La afinidad por las danzas bolivianas en una comuna limítrofe con dicho país, como lo es Calama, tiene un profundo significado, porque muchos promesantes que integran este tipo de agrupaciones justamente reivindican sus propios orígenes o ancestros bolivianos mediante la danza.

En este sentido, es posible sostener que aquellos/ as promesantes que interpretan danzas de influencia boliviana reciente parecieran desarrollar un alto nivel de implicación con lo "representado" en la danza, al punto de llegar asumir una "representación" (con carga política) de lo boliviano. Estos/as promesantes que desarrollan un alto grado de conciencia sobre su "bolivianidad" también parecen tener muy claras las consecuencias políticas implicadas en esta "representación". Muchos promesantes de Bailes de influencia boliviana reciente me han manifestado, por ejemplo, que comparten las críticas que desde Bolivia se plantean al hecho de que en Chile se interpreten danzas que proceden del folclore boliviano. De ahí que la fidelidad por los productos, indumentarias e incluso formas de interpretación musical "bolivianas" resulten ser elementos claves en la performance, ya que de esta manera se legitima la práctica de este tipo de danzas a partir de una cierta noción de autenticidad. En este mismo sentido, cabe destacar que por lo general las musicalidades que dan vida a las danzas de influencia boliviana reciente tienen una notable presencia en las prácticas cotidianas de los/as promesantes, como pueden ser celebraciones familiares, fiestas en discotecas e incluso conciertos; prácticas que, generalmente, no se encuentran presentes en la musicalidad de Bailes de antigua estirpe o de creación local ${ }^{19}$.

La puesta en escena de la dualidad "chileno/ boliviano" por las danzas promesantes constituye, a mi parecer, uno de los ámbitos más relevantes a partir del cual la población calameña y loína va generado sus propias estrategias de reafirmación, pero también de posible crítica hacia la hegemonía de este dualismo étnico/nacional. Pareciera ser que mediante la corporización de las categorías y significados presentes en el dualismo "chileno/ boliviano", los/as promesantes están intentando generar espacios donde los sentidos de la mezcla comiencen a tener cabida; especialmente en un país como Chile, el que se ha construido sobre una rígida pero ficticia idea de homogeneidad étnica y sociocultural.

\section{Comentarios Finales}

En los imaginarios de los/as promesantes calameños/as prevalece una forma generalizada de clasificación étnico/nacional de las danzas que ejecutan, la que tiende a establecer diferencias entre lo "chileno" y lo "boliviano". Por una parte, existe un gran segmento de danzas consideradas como "chilenas" y que se dividen en danzas de "antigua estirpe" y de "creación local". Ambos estilos comparten patrones coreográficos y rítmicos, así como también una forma de concebir la performance a partir de un sentido ascético, más cercano a la humildad y la sobriedad. Por otra parte, existe otro gran segmento de danzas que tienen como denominador común el hecho de ser consideradas como danzas "bolivianas". Estas además suelen ser agrupaciones que cuentan con una gran cantidad de integrantes, asumiendo la performance danzada a partir de una consideración festiva, donde el lujo y las demostraciones de jovialidad, sensualidad y alegría resultan fundamentales. 
A partir de los dos casos representativos que se han abordado en el desarrollo de este trabajo, se ha podido indagar con mayor grado de detalle en las singularidades de dicha diferenciación étnico/nacional de las danzas, pudiéndose constatar un fenómeno ciertamente interesante: mientras lo "boliviano" en el imaginario nacional chileno -construido desde el centro y sur del país- es considerado como un punto de referencia para la construcción de alteridad (lo "boliviano" se asocia a lo indio y, por lo mismo, a lo atrasado e inferior en términos no solo materiales sino que también étnico/raciales); en el caso de algunas danzas promesantes de Calama, lo "boliviano" es considerado como un punto de referencia identitaria e incluso como un modelo cultural a seguir. Y es que en el fondo, para muchos de estos/as promesantes se trataría nada más ni nada menos de danzas que pertenecen a su propia identidad cultural. Este asunto, evidentemente, introduce importantes tensiones en el imaginario nacional hegemónico, donde lo "chileno" es considerado como lo moderno, lo deseable y, por lo mismo, el único punto de referencia válido.

Ahora bien, este mecanismo de distinción y resignificación es interesante no solo por su incidencia en el plano meramente discursivo, sino que también en el plano de las disposiciones corporales que tensionan el habitus promesante tradicional relacionado con la actitud ascética y humilde. De esta manera, lo "boliviano" estaría indefectiblemente asociado a lo que también se denominan como las danzas de "carnaval"; danzas que -como hemos destacado anteriormente- desarrollan una gestualidad y un patrón coreográfico que marca evidentes diferencias con una tradición promesante más asociada a las danzas de antigua estirpe y de creación local.
Resulta evidente que las consideraciones étnico/ nacionales están ancladas en el entorno de actividad práctica de las danzas promesantes; el gesto define a la categorización tanto como la categorización definen al gesto, en un proceso de constitución recíproca. De esta forma, la relación entre las danzas promesantes y los procesos de construcción de identidades no tiene tanto que ver con la procedencia efectiva o construida de la danza, o con su valor en tanto posible emblema de identidad, sino que tiene que ver más bien con su capacidad de incidir de manera práctica y a nivel corporal en la articulación y reformulación constante de las identidades sociales. En definitiva, la mirada que reivindica la dimensión performativa de las danzas promesantes $-y$ que hemos intentado delinear en este trabajo- permite asentar una vía alternativa que permita comprender a la danza no solo como un reflejo de las identidades, sino que también como un mecanismo constructor de las mismas.

\section{Agradecimientos}

A los/as integrantes de los Bailes Religiosos promesantes a la Virgen Guadalupe de Ayquina, especialmente al Baile Hindú de Chuquicamata y a su caporal Alberto Palma y familia. A Domingo Aguilar, antiguo promesante y entrañable compañero de travesías por Calama y el Alto Loa. A la Dra. Josefina Roma, a la Dra. Montserrat Clua, a la Profesora Montserrat Garrich y al Dr. Tristán Platt, por sus valiosos comentarios y orientaciones. A Amy Muñoz, por su ayuda en la elaboración de los diagramas. A Max Ropert, por su valiosa colaboración en los registros audiovisuales de los tunos de baile en Ayquina 2012. Y a los evaluadores anónimos de Diálogo Andino, por sus valiosas críticas y sugerencias.

\section{Referencias Citadas}

Abercrombie, T.

1992 La fiesta del carnaval postcolonial en Oruro. Clase, etnicidad y nacionalismo en la danza folklórica. Revista Andina, 10 (2):279-352.

Abercrombie, $\mathrm{T}$.

1996 Q'aqchas and la plebe in "rebellion": carnival vs. lent in 18th-century Potosí. Journal of Latin American Anthropology, 2 (1):62-111.

Abercrombie, $\mathrm{T}$.

2003 Mothers and mistresses of the urban bolivian public sphere: postcolonial predicament and national imaginary in Oruro's carnival. En After Spanish Rule: Postcolonial Predicaments of the Americas, editado por Mark Thurner y Andrés Guerrero, pp. 176-220. Duke University Press, Durham and London.

Abercrombie, $\mathrm{T}$.

2006 Caminos de la Memoria y del Poder. Etnografía e Historia en una Comunidad Andina. Instituto Francés de Estudios Andinos, Instituto de Estudio Bolivianos, Cooperación ASDI-SAREC, La Paz.

Aguirre, J.M.

1967 Festividad de nuestra señora de Guadalupe de Ayquina. Revista de la Universidad del Norte, 4: 103-111.

Barth, F., comp.

1976 Los Grupos Étnicos y sus Fronteras. La Organización Social de las Diferencias Culturales. Fondo de Cultura Económica, México D.F. 
Bourdieu, P.

2012 La Distinción. Criterios y Bases Sociales del Gusto, $3^{\text {a }}$ edición. Taurus, Madrid.

Campos, L.

2013 Repetición y performance en la fiesta de la Oración por Chile en La Tirana. Revista Estudios Cotidianos, 1 (2):146-159.

Campos, L., J. Millar, F. Ramírez, T. Téllez, R. Jiménez, y E. Pavez. 2009 Cuyacas. Música, Danza y Cultura en una Sociedad Religiosa de la Fiesta de La Tirana. Salesianos, Santiago de Chile.

Cánepa, G.

1998 Máscara, Transformación e Identidad en los Andes. La Fiesta de la Virgen del Carmen, Paucartambo-Cuzco. Fondo Editorial Pontificia Universidad Católica del Perú, Lima.

Cánepa, G.

2001 Introducción. Formas de cultura expresiva y la etnografía de "lo local". En Identidades Representadas. Performance, Experiencia y Memoria en los Andes, editado por Gisela Cánepa, pp. 11-35. Fondo Editorial Pontificia Universidad Católica del Perú, Lima.

Cárdenas, $\mathrm{C}$.

2009 El poder de las polleras. Performatividad, representación y poder entre las bailarinas de morenada del Gran Poder. En Gran Poder: La Morenada, editado por Rossana Barragán y Cleverth Cárdenas, pp. 255-418. Instituto de Estudios Bolivianos, Convenio UMSA-ASDI/SAREC, La Paz.

Castro, V.

2009 De Ídolos a Santos. Evangelización y Religión Andina en los Andes del Sur. DIBAM, Facultad de Ciencias Sociales, Universidad de Chile, Santiago de Chile.

Castro, V. y J.L. Martínez

1996 Poblaciones indígenas de Atacama. En Etnografía. Sociedades Indígenas Contemporáneas y su Ideología, editado por Jorge Hidalgo et al., pp. 69-109. Editorial Andrés Bello, Santiago de Chile.

Chamorro, A.

2013 Carnaval andino en la ciudad de Arica: Performance en la frontera norte chilena. Estudios Atacameños, Arqueología y Antropología Surandinas, 45:41-54.

Csordas, $\mathrm{T}$.

2010 Modos somáticos de atención. En Cuerpos Plurales. Antropología de y desde los Cuerpos, coordinado por Silvia Díaz, A. Citro, pp. 83-104. Biblos/Culturalia, Buenos Aires.

2009 Los Andes de bronce. Conscripción militar de comuneros andinos y el surgimiento de las bandas de bronces en el norte de Chile. Historia, 42:371-399.

Díaz, A.

2011 En la pampa los diablos andan sueltos. Demonios danzantes de la fiesta del santuario de La Tirana. Revista Musical Chilena, LXV (216):58-97.

Díaz, A. y P. Lanas

2013 Al compás de un danzar telúrico. Pampinos e indígenas en la fiesta de la Virgen de La Tirana, 1900-1950. En La Sociedad del Salitre. Protagonistas, Migraciones, Cultura Urbana y Espacios Públicos, compilado por Sergio González, pp. 279-300. RIL Editores, Universidad Arturo Prat, Universidad de Valparaíso, Universidad Católica del Norte, Santiago de Chile.
Díaz, A., L. Galdames y W. Muñoz

2012 Santos patronos en los Andes. Imagen, símbolo y ritual en las fiestas religiosas del mundo andino colonial (siglos XVI-XVIII). ALPHA, 35:23-39.

Estenssoro, J.C.

1992 Los bailes de los indios y el proyecto colonial. Revista Andina, 10 (2):353-389.

Gavilán, V. y A. Carrasco

2009 Festividades andinas y religiosidad en el norte chileno. Chungará, Revista de Antropología Chilena, 41 (1):101-112.

González, C., C. Garrido y S. Dip.

2007 Ritmos de la Tierra, Danzas Cósmicas. Bailes Religiosos de la Provincia de El Loa. CORE Región de Antofagasta, Antofagasta.

González, S.

2006 La presencia indígena en el enclave salitrero de Tarapacá: una reflexión en torno a la fiesta de La Tirana. Chungará, Revista de Antropología Chilena, 38 (1):35-49.

Guerrero, B.

2007 La Tirana. Chile. Instituto Iberoamericano del Patrimonio Natural y Cultural, Quito.

Gundermann, H.

2003 Sociedades indígenas, municipio y etnicidad: La transformación de los espacios políticos locales andinos en Chile. Estudios Atacameños, 25:55-77.

Gundermann, $\mathrm{H}$.

2004 Inicios de siglo en San Pedro de Atacama: Procesos, actores e imaginarios en una localidad andina. Chungará, Revista de Antropología Chilena, 36 (1):221-239.

Jackson, M.

2010 Conocimiento del cuerpo. En Cuerpos Plurales. Antropología de y desde los Cuerpos, coordinado por Silvia Citro, pp. 59-82. Biblos/Culturalia, Buenos Aires.

Laan, E.

1993 Bailar para sanar. Estudio de la praxis de la peregrinación de los bailes religiosos del norte de Chile. Cuaderno de Investigación Social CREAR, 34:1-89.

Lavín, C.

1948a. Nuestra señora de Las Peñas. Fiesta ritual del norte de Chile. Revista Musical Chilena, 4 (31):12-36.

Lavín, C.

1948b. Nuestra señora de Las Peñas (conclusión). Revista Musical Chilena, 4 (32):27-40.

Lavín, C.

1950 La Tirana. Fiesta ritual de la provincia de Tarapacá. Revista Musical Chilena, 6 (37):12-36.

Letelier, M.

2010 Teatralidad en la fiesta de Nuestra Señora Guadalupe de Ayquina: poiesis, metáfora y representación del baile religioso. Cátedra de Arte, 8:79-97.

Martínez, J.L.

1985 La formación del actual pueblo de Toconce. Siglo XIX. Chungará, 15:99-124.

Martínez, R.

1988 Quelques Aspects Musicaux de la Fiesta de La Tirana (Chili). Mémoire de Maitrise, Université de Paris X-Nanterre, Paris.

Mendoza, Z.

2000 Shaping Society through Dance: Mestizo Ritual Performance in the Peruvian Andes. The University of Chicago Press, Chicago.

Mostny, G.

1948 La Fiesta de Ayquina. Mecanografiado, inédito. 
Núñez, L.

2004 La Tirana del Tamarugal. Ediciones Universitarias de la Universidad Católica del Norte, Antofagasta.

Platt, T.

1996 Los Guerreros de Cristo. Cofradías, Misa Solar y Guerra Regenerativa en una Doctrina Macha (siglos XVIII-XX). ASUR Antropólogos del Surandino, Plural Editores, La Paz.

Poole, D.

1990 Accommodation and resistance in andean ritual dance. TDR/The Drama Review, 34 (2):98-126.

Romero, R.

1988 Development and balance of peruvian ethnomusicology. Yearbook for Traditional Music, 20:146-157.

Royce, A.

2002 The Anthropology of Dance, $2^{\mathrm{a}}$ edición. Indiana University Press, Bloomington.

Spivak, G.

2009 ¿Pueden Hablar los Subalternos?, traducción y edición crítica de Manuel Asensi Pérez. Museu d'Art Contemporani de Barcelona, Barcelona.

Tennekes, H. y J. van Kessel.

1986 Estructura y antiestructura en el peregrinaje a La Tirana y otros santuarios del Norte Grande de Chile. Cuaderno de Investigación Social CREAR: Religiosidad popular en el Norte de Chile, 18:8-38.

Turner, V.

1987 The Anthropology of Performance. PAJ Publications, New York.
Uribe, $\mathrm{J}$.

1963 La Tirana de Tarapacá. Mapocho, 2:83-122.

Van Kessel, J.

1973 Los cantuarios de La Tirana, Aiquina y Las Peñas. Revista de la Universidad Técnica del Estado, 11-12:199-215.

Van Kessel, J.

1975 Bailarines en el Desierto. Tres Sociedades de Bailes. Mecanografiado, Antofagasta.

Van Kessel, J.

1982 Danzas y Estructuras Sociales de los Andes. Instituto de Pastoral Andina, Cuzco.

Van Kessel, J.

1984 Los bailes religiosos del norte chileno como herencia cultural andina. Chungará, 12:125-134.

Van Kessel, J.

1992a Aica y la Peña Sagrada. El Jote Errante, Iquique.

Van Kessel, J.

1992b. Cuando Arde el Tiempo Sagrado. Hisbol, La Paz.

Wachtel, N.

1976 Los Vencidos. Los Indios del Perú frente a la Conquista Española (1530-1570). Alianza Editorial, Madrid.

Wolf, J.

2012 Tradición y wayno para soplar: Las lakitas en los bailes religiosos de Arica. En Lakitas en Arica. Zampoñas, Sopladores y Ritmos en el Norte de Chile, editado por Gerardo Mora, pp. 107-115. AZAPA Producciones, Arica.

\section{Notas}

1 Por razones de claridad expositiva denominaré como "Bailes Religiosos" o simplemente "Bailes" (con mayúscula) a las agrupaciones o sociedades de promesantes, reservando el término "baile" (con minúscula) para referirme, de manera general, a la actividad humana y fisiológica de ejecutar una determinada danza.

2 El concepto de "corporización" se refiere a la traducción de embodiment propuesta por Silvia Citro (2010), e indica la existencia de una tensión metodológica entre un tipo de aproximación semiótica o textualista del cuerpo (que tiende a percibirlo como soporte transmisor de significados culturales) y otro tipo de aproximación fenomenológica que reconoce al embodiment -o corporización- "como la condición existencial en la que se asientan la cultura y el sujeto" (Csordas 2010:84).

3 El posicionamiento básico que se asume a la hora de abordar el siempre complejo tema de la identidad está inspirado en el clásico texto de Fredrik Barth (1976), donde se propone un importante giro en la concepción tradicional de las identidades étnicas. En dicho trabajo se considera que lo más relevante para comprender los fenómenos de adscripción identitaria no son los contenidos socioculturales "objetivos" de cada grupo, sino que más bien es necesario comprender "cómo actúan los otros en cuya compañía se interactúa y con los cuales se es comparado y qué identidades alternativas y conjuntos de normas están disponibles para el individuo" (Barth 1976:31). Es así como se sostiene que las identidades colectivas se construyen en la interacción y en las relaciones de alteridad; y precisamente por ello es que, en este trabajo, se considera que las adscripciones identitarias "chilenas" y "bolivianas" se construyen a partir de una relación o juego de alteridades, en ellas las danzas promesantes se han ido emplazado como uno de los soportes privilegiados para dar cuenta de dicha construcción social.

4 A modo de ejemplo, Díaz y Lanas (2013) señalan que para el caso de la fiesta de La Tirana, en pleno contexto modernizador a comienzos del siglo XX, la oficialidad eclesiástica revitalizó la institución colonial de la cofradía para así poder "regular e institucionalizar el culto Mariano y encauzar manifestaciones que podían distanciarse de los dogmas eclesiásticos" (2013:292).

5 Como resulta evidente, Juan van Kessel es uno de los mayores exponentes de la tesis de la "supervivencia" aplicada al estudio de los Bailes Religiosos del Norte Grande. Parte de su planteamiento general puede resumirse en las siguientes palabras: "[se] puede llegar a visualizar la supervivencia activa de fuertes elementos autóctonos que subsisten bajo la superficie de las aguas turbias de la Colonia y aún bajo los sedimentos fangosos de una dudosa política republicana de culturización y de chilenización. Es así como se podrá reconocer en las estructuras coreográficas una real presencia de los elementos básicos de la cosmovisión andina: La conciencia de lo trascendental y su orientación andina correspondiente; su afirmación del orden cósmico y su angustia por la amenaza del Kuti, o caos; su sensibilidad del misterio de la vida y de la abundante fertilidad de la santa y universal madre tierra; su ansiedad por una vida plena y duradera que trasciende la existencia individual y se 
hunde en lo colectivo" (Van Kessel 1982: viii). Con algunos matices, pero siguiendo la misma línea de análisis de Van Kessel, podemos mencionar por ejemplo los trabajos de Erik Laan (1993) y Bernardo Guerrero (2007), entre otros investigadores. Más allá de que la propuesta del presente artículo busca establecer una mirada crítica en relación con la tesis de la "supervivencia", es justo reconocer la importancia de los trabajos de Van Kessel y su enorme aporte al desarrollo de diversas metodologías para la investigación de este importante fenómeno, entre ellas se destaca la riqueza de las estructuras coreográficas y la aplicación de censos de Bailes Religiosos; dos estrategias metodológicas de las que se ha beneficiado mi propio trabajo.

6 La siguiente descripción y análisis se sustenta en un trabajo de observación-participante realizado en la fiesta de Ayquina con el Baile Religioso Hindú de Chuquicamata, durante el 3 y 9 de septiembre de 2012. Cabe destacar que el trabajo de observación-participante con esta y otras sociedades de Bailes Religiosos no se ha limitado únicamente al contexto festivo, sino que también se ha contemplado una presencia en las diversas actividades que forman parte del ciclo anual de preparación de las agrupaciones en la ciudad de Calama. Este trabajo de campo se inició en febrero del 2008 y se ha continuado hasta hoy con lapsos variables de presencia y ausencia.

7 Existe una segunda fiesta, la del 12 de diciembre, que es considerada como la fiesta "chica" y en la que participan principalmente personas relacionadas con la comunidad indígena de Ayquina y otras comunidades aledañas. Esta fiesta "chica" podría considerarse como la fiesta "patronal", en contraposición a la fiesta de septiembre que sería la fiesta del "santuario".

8 Esta "visita" es correspondida por la imagen de la Virgen de Ayquina para la fiesta de San Santiago de Toconce entre el 23 y 26 de julio. Las visitas de imágenes, evidentemente, también implican la mantención de ciertos lazos de unión entre los comuneros de Ayquina y Toconce; dos comunidades que tendrían orígenes comunes (Martínez 1985; Castro y Martínez 1996).

9 El concepto de "performance" o "performance cultural" es abordado en este trabajo desde la perspectiva propuesta por Victor Turner en su señero texto The Anthropology of Performance (1987). La emergencia de este concepto en el campo de los estudios antropológicos tuvo como objetivo delimitar cierto tipo de fenómenos socioculturales que exceden los límites de la expresividad verbal (como danzas, músicas, teatro, dramas, etc.). Su desarrollo teórico se orienta hacia la superación de los paradigmas simbólico-textualistas, reivindicando la dimensión práctica de la actividad humana como instancia igualmente constitutiva de los fenómenos sociales. En este trabajo utilizo el concepto de performance sin cursivas, puesto que si bien se trata de un término anglosajón, en la actualidad se encuentra plenamente legitimado como un anglicismo más en la lengua castellana.

10 La clasificación de danzas que sostengo es deudora de otras propuestas, como por ejemplo la de Lautaro Núñez para el caso de la fiesta de La Tirana (2004:108-141), quien, a partir de la cultura material, plantea la existencia de dos grandes tipos de danzas promesantes a nivel nortino: los "bailes tradicionales o de ancestro colonial" (mascaradas, morenadas, chunchos, pastoralistas y chinos) y los "bailes más recientes" (zambos caporales, pieles rojas, cosacos, gauchos, españoles, marinos, etc.). Así mismo, Juan van Kessel (1982:25) propuso en su momento la existencia de dos tipos de bailes: "antiguos" y "nuevos". Por su parte, Díaz y Lanas (2013) señalan también la existencia de tres tipos: "antiguos bailes andinos" (morenos, chunchos y cuyacas), los bailes chinos provenientes del Norte Chico y otro tipo de bailes surgidos a partir de la influencia del cine y otros elementos más ligados a la modernidad (indios siux, dakotas, pieles rojas, etc.) que se proyectaron como los "otros indios" (Díaz y Lanas 2013:296). Si bien la propuesta que acá sostengo rescata algunos elementos centrados en la cultura material y en el desarrollo histórico de las agrupaciones, también pretende enfatizar en los significados elaborados por los/as mismos/as promesantes, así como también en los soportes propios de la actividad danzada como son las coreografías, los pasos y los estilos musicales.

11 En este grupo hay danzas que efectivamente provienen de un contexto andino-boliviano, como son los Bailes chunchos, pero sin embargo, y debido al profundo arraigo que tienen en la zona, son comprendidas como igualmente "chilenas" por parte de los promesantes.

12 Un conocido caso de "creación local" es el de la invención del primer Baile de Pieles Rojas devoto de la Virgen de La Tirana en la ciudad de Iquique, cuyo origen es claramente cinematográfico (cf. Uribe 1963:89-91; Díaz y Lanas 2013:295-296). La cercanía de la danza ejecutada por este tipo de Baile, con aquellas que he denominado como de "antigua estirpe" es reafirmada por Uribe, cuando señala -respecto del propio Baile Pieles Rojas iquiqueño- que "en sus saltos y vueltas se parecen a los chunchos, de los cuales han derivado" (1963:91).

13 Los ejemplos que presentaré se sustentan en descripciones densas realizadas a partir de observaciones directas y registros audiovisuales realizadas durante la fiesta de Ayquina de 2012.

14 El Baile Religioso Hindú fue fundado el 6 de marzo de 1949 por don Eduardo Vela, fallecido trabajador del mineral de Chuquicamata.

15 Este movimiento o mudanza -muy recurrente en las danzas promesantes- es denominado en ocasiones como "media luna" (Van Kessel 1982b: 56).

16 Spivak (2009:56) sostiene que el significante "representación" tiene dos acepciones. La primera ("representación") quiere decir "hablar por" alguien tal y como sucede en el campo político; y la segunda ("representación") quiere decir "volver a presentar algo" tal y como sucede en el campo de arte o la filosofía.

17 Este Baile fue fundado en la ciudad de Calama el 21 de septiembre de 1995, por su actual caporal, don Ángel Alburquenque, y otros integrantes de su familia escindidos del Baile Gran Diablada Calameña.

18 El ritmo de saya -según señala Zoila Mendoza- es un estilo musical "muy alegre y de tempo rápido, con un compás binario dominante, y un número limitado de frases de diferentes longitudes, las cuales son reiteradas muchas veces. Este estilo de saya es una versión modificada del que ejecutan actualmente los afrobolivianos, el que ha adquirido un papel central en el movimiento negro en ese país" (2000:211). Interpretado con distintas velocidades, el ritmo de saya es la base de una serie de danzas muy 
populares en el área centro-sur andina, como son los caporales, zambos, negritos y tuntunas. Si bien es cierto que el patrón rítmico es predominantemente binario, es necesario destacar que la interpretación del ritmo implica una acentuación en la nota débil del compás dando forma a un patrón rítmico de síncopa. Así mismo, la diferencia en la velocidad o tempo con que es interpretado el ritmo implica un rasgo que otorga una variación en los estilos y procedencias. En relación con este último aspecto, algunos músicos de bandas de bronce me han comentado que, en la interpretación del ritmo de la morenada, los músicos de origen boliviano tienen la habilidad de tocarlo en un tempo mucho más lento en relación con un músico chileno. Como se puede ver, el tempo también constituye un elemento constructor de diferencias entre lo "chileno" y lo "boliviano"; lo significativo, en este caso, es que la aspiración de muchos músicos nortinos chilenos es poder llegar a interpretar el ritmo a la manera boliviana, ya que se considera que aquella es la forma más correcta de hacerlo.

19 Quizás una excepción a esta regla es el caso del Baile Religioso Mexicano (de creación local), donde algunos de sus participantes y músicos forman parte además de un grupo de "charros" en la ciudad de Calama. 
